\title{
LLNL Participation in the Fourth International Interlaboratory Comparison Test (Round Robin 4)
}

\author{
Raymond R. McGuire \\ Jeffrey S. Haas \\ Richard E. Whipple \\ Brian D. Andresen \\ with \\ Rodney J. Eagle
}

November 1993

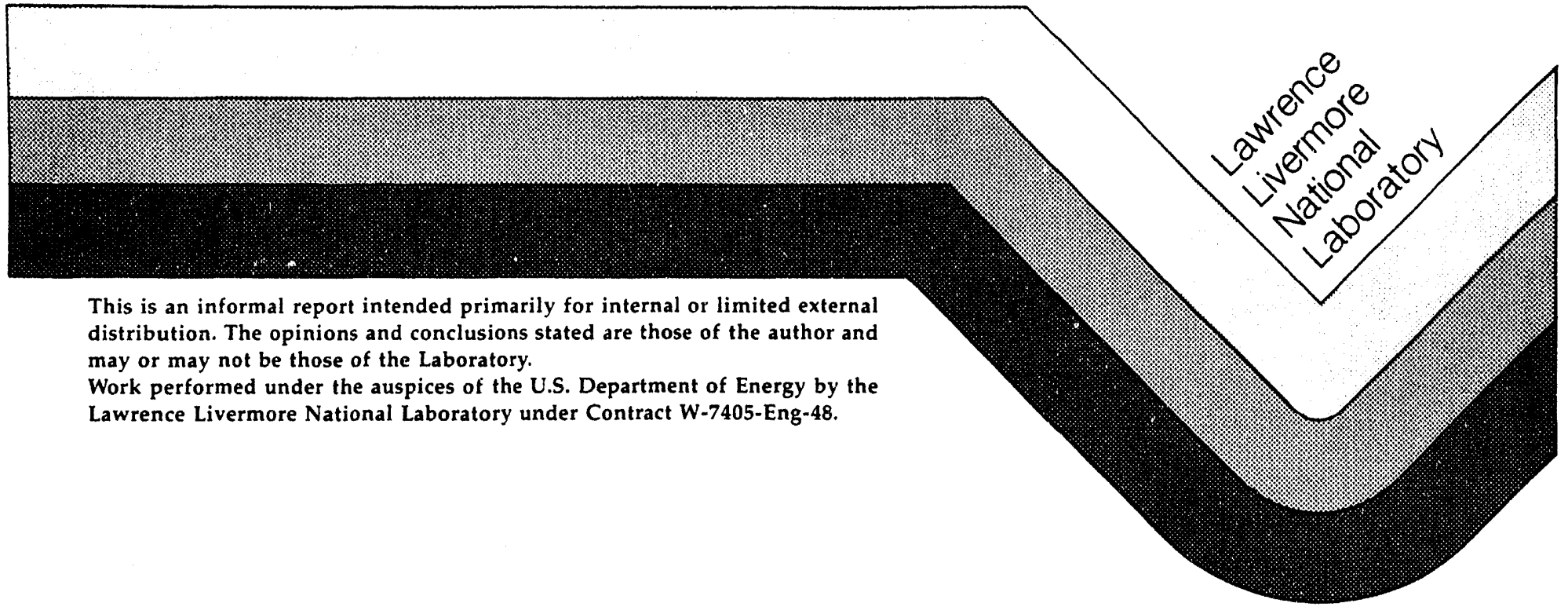




\section{DISCLAIMER}

This document was prepared as an account of work sponsored by an agency of the United States Government. Neither the United States Government nor the University of Calfformia nor any of their employees, makes any warranty, express or implied, or assumes any legal liablitty or responsibility for the accuracy, completeness, or usefulness of any information, apparatus, product, or process disclosed, or represents that its use would not infringe privately owned rights. Reference herein to any spectific conmercial products, process, or service by trade name, tradernark, manufacturer, or otherwise, does not necessarily constitute or impiy its endorsement, recommendation, or favoring by the United States Government or the University of Callfornia. The views and opinions of authors expressed herein do not necessarily state or reflect those of the United States Government or the University of California, and shall not be used for advertising or product endorsement purposes.

This report has been reproduced directly from the best available cops.

Available to DOE and DOE contractors from the Ofirce of Scientific and Technical Information P.O. Box 62, Oak Ridge, TN 37831

Prices available from (615) 576-8401, FTS 626-8401

Available to the public from the

National Technical Information Service

U.S. Department of Commerce

5285 Port Royal Rd.

Springtield, VA 22161 


\section{LAWRENCE LIVERMORE NATIONAL LABORATORY PARTICIPATION IN THE FOURTH INTERNATIONAL INTERLABORATORY COMPARISON TEST ROUND ROBIN 4}

\section{Introduction:}

The Lawrence Livermore National Laboratory (LLNL), at the request of the international Round Robin coordinating laboratory, the University of Helsinki, Finland, undertook the preparation of the samples to be analyzed by laboratories participating in Round Robin 4. Our initial proposal was to limit the exercise to soil samples. However, at the request of many of the participants, we agreed to also include water samples.

The proposal to focus on soil samples was based on our experience of the difficulty in extracting polar compounds from various soil types. Since, as we believe, the soil samples that are collected during the course of inspections under the CWC are most likely to contain the polar decomposition products of $\mathrm{CW}$ agents, not the agents themselves, this exercise was particularly relevant.

The samples for Round Robin 4 were produced with the idea of promoting the comparison of techniques for processing environmental samples (soil and water) for instrumental analysis. In other words, a comparison of the effectiveness of the various extraction methods used in the participating laboratories. Thus, each of the sample substrates was spiked with the same four compounds to a concentration of 10 parts per million (ppm) or more depending on the added material.

The selection of precursor chemicals and decomposition products rather than actual $\mathrm{CW}$ agents simplified the problem of sample transportation from LLNL to the participating labs. As the samples were not hazardous materials, they could be sent by commercial air transport.

\section{Sample (Spike) Materials:}

The compounds selected for spiking the Round Robin 4 samples were to be examples of the decomposition products associated with $\mathrm{CW}$ agents that might be found during the course of a CWC inspection. They also represented a range of precursor materials. These compounds are characteristically polar; containing acidic or basic moieties or both. This polar nature gives them low solubility in the relatively non-polar solvents usually used for extracting organic analytes. It also gives them moderate water solubility and makes them likely to adhere rather strongly to certain types of soil. The compounds selected were:

1.) Benzilic acid (BA) - a product of $B Z$ decomposition,

2.) 3-Quinuclidinol (3-Q) - a product of $B Z$ decomposition,

3.) Diisopropylamino ethanol (DIPAE) - from VX, and

4.) Methylphosphonic acid (MPA) - form any $G$ or $V$ agent containing a methylphosphorous bond. Methlyphosphonic acid is the only one of the four that cannot also be a precursor. 
The spiking compounds were all purchased from Aldrich Chemical Co., were of the highest purity commercially obtainable ( $99 \%$ or greater), and were used without further purification.

\section{Sample Substrates (Soil and Water):}

Three types of soil with as different characteristics as practical were chosen as substrates for RR-4. They were:

1.) Soil labeled "SA"- This is a typical "forest" type of soil with a high humus content. It was collected in a wooded area near Livermore, CA., USA. A neutral water extract of this soil showed a $\mathrm{pH}$ of 6.5 or very slightly acidic;

2.) Soil labeled "SB"- This is a "desert alkaline" soil with a high carbonate content collected near Albuquerque, New Mexico. A neutral water extract of this soil gave a pH of 8.3 or basic; and

3.) Soil labeled "SN"- This is a "sandy loam" with a moderate clay content along with silica (sand) and silt. It was collected from grassland in the Sacramento River delta. A neutral water extract showed an essentially neutral $\mathrm{pH}$ of 6.8 .

The $\mathrm{pH}$ was determined by adding neutral $(\mathrm{pH} 7.0)$ water to a $50 \mathrm{~g}$ sample of soil, mixing, and allowing the sealed container to sit one hour before measuring the $\mathrm{pH}$ with an Orion $\mathrm{pH}$ meter that had been freshly calibrated against $\mathrm{pH} 4,7$, and 12 buffers.

The water samples were from an aqueduct which supplies the Livermore Valley. The water was collected upstream of the treatment plant and is thus representative of Tuolomne River water. It is somewhat basic with a pH of 8.2.

Since the RR-4 laboratories wished to evaluate field extraction of a collected water sample using a solid phase extractant, we included a sample adsorbed on a C-18 extraction cartridge. The C-18 cartridge was an Alltech "Ultra-Clean" 1 gram cartridge of $6.0 \mathrm{ml}$ capacity.

\section{Preparation of RR-4 Samples:}

Spiking Solutions:

Solutions of the four spike compounds were made using HPLC grade water purchased from Burdick and Jackson. The concentrations of MPA, DIPAE and BA were 0.5 grams per liter. Because we had experienced some difficulty in extracting the $3 \mathrm{Q}$, its concentration was made 1.0 gram per liter, or twice that of the other compounds. This solution was used to prepare the water and cartridge samples. Before adding the solution to the soils, the concentration of $3 Q$ was again doubled to 2.0 grams per liter.

\section{Soil Samples:}

The soils were first sieved through a 2 millimeter (pore size) screen to remove any large stones, sticks, grasses, etc. They were then dried at $65^{\circ} \mathrm{C}$ to constant weight (approximately 48 hours) and divided into 50 gram aliquots. One milliliter of the spiking 
solution was then added to each of the aliquots. After "drying" at room temperature for approximately 60 hours, each of the samples was homogenized on a vibrating mill for 30 minutes. This procedure was previously shown to produce quite homogeneous samples. The final concentrations of the spiking materials in the soil were 10ppm for the MPA, DIPAE and $\mathrm{BA}$, and $40 \mathrm{ppm}$ for the $3 \mathrm{Q}$.

\section{Water Samples:}

The aqueduct water was filtered through a 1.0 micron nucleopore filter and stored at about $8^{\circ} \mathrm{C}$ until extracted. Methylene chloride was added at a concentration of 0.5 $\mathrm{ml} /$ liter to the water that was not to be used for preparing the cartridge. One milliliter of the spiking solution was then added to each $49 \mathrm{ml}$ aliquot of the filtered water. This led to a final concentration of the spiking material in the water samples of 10ppm of MPA, DIPAE and BA, and 20ppm of $3 \mathrm{Q}$.

\section{Cartridge Samples:}

Fifty milliliter water samples were made up in the same manner described above except that the methylene chloride was not added. These 50 milliliter aliquots of the spiked water were then passed through $\mathrm{C}$-i 8 cartridges (one cartridge per aliquot). The elution time was 3-3.5 minutes. The eluent was collected, packaged and included in the sample set.

The $\mathrm{C}-18$ cartridges had been previously conditioned with three $10 \mathrm{ml}$ aliquots of methanol followed by three $10 \mathrm{ml}$ aliquots of high purity water.

\section{Characterization experiments:}

Prior to the preparation of the samples for shipping to the laboratories participating in RR-4, we performed a series of experiments to characterize both the analytes and the spiked samples. These experiments consisted of mass spectral analysis of the trimethylsilyl (TMS) derivatives of the spike compounds, extraction of spiked soil and water samples with a variety of solvents immediately after preparation and after storage at ambient temperature, and analysis of the TMS derivatives of the extracts by GC / MS. These experiments were done in order to determine:

1.) a solvent system which would he effective for extracting the target compounds from the selected soil, water, and C-18 cartridge substrates,

2.) how to avoid interferences due to extracting extraneous compounds along with the target compounds,

3.) self-polymerization of the target compound,

4.) a system that dissolved all four target compounds,

5.) a reasonable concentration for the spiking compounds on a given substrate, and

6.) any subsequent reaction and/or decomposition of the target compounds that might occur during transportation or storage of the samples prior to analysis.

The results of these experiments convinced us that the analytes would not decompose by any appreciable amount during transit and storage. 


\section{Derivatization:}

Three of the four spiking compounds, benzilic acid, methylphosphonic acid and, 3quinuclidinol, are solid crystalline materials at room temperature and are relatively nonvolatile. The fourth compound, diisopropylamino ethanol, is a liquid. However all four compounds are quite polar and are not amenable to gas chromatography (GC) analysis using only methyl silicone columns. Therefore, to improve GC characterization, all extracts, spiking solutions and blanks were derivatized using N, O-bis(trimethylsilyl) trifluoroacetamide (BSTFA) before analyses. The procedure used for derivatizing with BSTFA was as follows:

1.) the extract, standard or blank material, was transferred to a reaction vial and taken to dryness under a helium purge at room temperature;

2.) BSTFA was added (typically $100 \mu \mathrm{L}$ ) to the vial which was then capped;

3.) the vial was then heated to $60^{\circ} \mathrm{C}$ for 15 minutes in a Pierce Reacti-Therm III heating module.

BS'TFA then replaced the active hydrogen from the $-\mathrm{OH},-\mathrm{SH},-\mathrm{NH}$, functional groups with a trimethylsilyl (TMS) group. This generated a volatile derivative suitable for GC/MS analysis.

\section{Instrumentation:}

The GC/MS analysis was performed on a Hewlett-Packard model 5890 gas chromatograph interfaced to a Hewlett-Packard model 5988 quadrupole mass spectrometer. The gas chromatograph was fitted with a 30 meter Alltech SE-30, 100\% methyl silicone capillary column, having an i.d. of $0.25 \mathrm{~mm}$ and a 0.25 micron film thickness. A splitless injection mode was used with a one minute residence time at $250^{\circ} \mathrm{C}$. The temperature program for the oven was: 10 minute hold time at $70^{\circ} \mathrm{C}$ followed by a ramp at $8^{\circ} \mathrm{C}$ per minute to $320^{\circ} \mathrm{C}$. Data acquisition began at 3.0 minutes for the underivatized samples and 9.5 minutes for the derivatized samples.

The mass spectrometer was operated using electron impact at $70 \mathrm{eV}$ and 300 micro amps, source temperature at $200^{\circ} \mathrm{C}$, and the interface temperature at $300^{\circ} \mathrm{C}$. The standards and protocols used to tune mass spectrometers according to EPA regulations are not currently used for the HP 5988 mass spectrometer. These regulations essentially detune the instrument in the mid to high $\mathrm{m} / \mathrm{z}$ range. Further, the quantification of the unusual compounds in current analyses is not required. However, a standard or a mixture of standards are always analyzed to ascertain the sensitivity of the assay and column performance. Internal standard(s) were added to the samples to monitor the efficiency of the sample preparation procedures. The tuning compound used for mass spectral calibration for both manual and autotune programs was perfluorotributylamine [PFTBA, $\left.\left(\mathrm{C}_{4} \mathrm{~F}_{9}\right)_{3} \mathrm{~N}\right]$. The default ions used for both tuning procedures were $\mathrm{m} / \mathrm{z} 69,219$, and 502 . Their standardized ratios were $100 \%, 40 \%, 2 \%$, respectively. The full width at half maximum (FWHM) relative peak widths of 69 and 502 must be the same $\pm 0.1 \mathrm{amu}$.

\section{Extraction Experiments--Soil}

1.) To the three sets of soil substrates, weighing 50.0 grams each, was added a $1.0 \mathrm{ml}$ aliquot $(50 \mu \mathrm{g} / \mathrm{ml})$ of a water solution of the four spiking compounds. This resulted in a 
final concentration at $1 \mu \mathrm{g}$ for each of the four compounds per gram of soil. In addition to the spiking compounds, naphthalene-d 8 was also added to give a final concentration of $1 \mu \mathrm{g}$ per gram of soil. This served as an internal marker in the total ion chromatogram (TIC). The substrates were allowed to dry for 24 hours and then homogenized before extraction.

Three sets of 10 gram aliquots from each of the three substrates were extracted using a solvent mixture of 3 parts isopropyl alcohol to one part methylene chloride. Each of the nine extracted fractions were concentrated to a final $100 \mu$ l volume from which $2 \mu \mathrm{l}$ aliquots were taken for injection into the GC/MS. A total time of approximately 36 hours had passed from the initial spiking of the substrates to their GC/MS analysis.

Examination of the resulting total ionization chromatograms (TIC's) for the underivatized fractions, shows no evidence of non-polar decomposition products in any of the substrates. The naphthalene-d8 marker was present in all extracts, appearing at a retention time of 15.7 minutes. Figure 1 is a TIC of the basic soil extract and is representative for all nine extracts. It shows the naphthalene-d8 internal standard as the major constituent along with many smaller peaks arising from the usual extracted organic material associated with soils.

The nine extracts were then taken to dryness and derivatized with $100 \mu \mathrm{L}$ of BSTFA in order to examine the polar, non-volatile compounds (and similar decomposition products). Again, $2 \mu$ l aliquots were injected into the gas chromatograph. Only the methylphosphonic acid (MPA) was found $(\mathrm{m} / \mathrm{z}=225,240)$, appearing at a retention time of 15.4 minutes. Figure 2 is a TIC representative of all nine extracts from the basic soil. Also, seen in this figure, is the TMS derivative of phosphate appearing at 19.2 minutes, characteristic of the basic soils.

These results led to the conclusion that either the spiked compounds (other than MPA) were decomposing before the soil was extracted or the extraction solvent was inefficient for these materials. The failure to detect any decomposition products seemed to suggest the need to investigate other solvents. We selected the acidic soil as the substrate and utilize a different extraction solvent, acetonitrile ( $\mathrm{ACN}$ ), for the next series of experiments.

2.) Two sets of acidic soil samples weighing 50 grams each were made up by adding a water solution of the spiking compounds to give concentrations of $10 \mu \mathrm{g}$ and $100 \mu \mathrm{g}$ per gram of soil respectively. Each spiked sample was allowed to dry for 72 hours under ambient conditions. Both samples were extracted following the same extraction procedures given above for the isopropyl alcohol / methylene chloride solvent system except that acetonitrile was used. A 10.0 gram portion from each substrate set was extracted, evaporated to dryness, and derivatized with $200 \mu \mathrm{l}$ of BSTFA. A $2.0 \mathrm{ml}$ aliquot of the spiking solution was also dried under helium purge and derivatized with $200 \mu \mathrm{l}$ of BSTFA. These two sample sets (the soil extract and the spiking solution) should have given comparable TICs since the concentration of spiking material is the same in both

The resulting TIC of derivatized spiking solution, is shown in Figures $3 \mathrm{a}$ and $3 \mathrm{~b}$. A mass spectral plot of each peak shows the characteristic $\mathrm{m} / \mathrm{z}$ ratios (Figures $3 \mathrm{c}-\mathrm{g}$ ) for the spiking compounds. The chromatographic retention times of the four target compounds are also shown. MPA has a retention time of 15.4 minutes, followed by 2- 
(diisopropyl-amino)ethanol (DIPAE) at 16.4 minutes, 3-quinuclidinol (3-Q) at 18.9 minutes, and benzilic acid (BA), two peaks occurring at 28.9 minutes for the monoderivatized and 29.2 minutes for its di-derivatized component.

The resulting TIC's from the extracts using acetonitrile as the extraction solvent are shown in Figures 4 and 5 for the two different concentrations of spiking material. Both chromatograms show low levels of the four spiking compounds (both 3-Q and BA at trace levels). Also shown, is a significant increase in the amount of extracted organic materials, when compared to the 3:1 (isopropyl alcohol to methylene chloride) extraction system. These results and comparisons between the TICs of the spiking solution and sample extracts, (Figures $3 \& 4$, respectively) reveal that acetonitrile is not the most appropriate solvent to remove these specific $\mathrm{CW}$-related compounds from soil samples.

3.) Modifications of the actual extraction procedure were then devised to compare extraction efficiencies between different substrates. A total of three extraction solvents were studied on the three different soil substrates. Each 50 gram substrate was again spiked using $1.0 \mathrm{ml}$ of the same spiking solution used in acetonitrile studies. This gave a concentration on the soils of $10 \mathrm{mg}$ per gram. Also, in order to monitor the potential aging and/or decomposition of the target compounds, the extractions were performed at set timed intervals; 24,48 , and 96 hours after the initial spiking.

Three sets of 10.0 gram samples from each of the three spiked substrates were extracted with their respective solvent mixture; 3:1 (isopropyl alcohol to methylene chloride), acetonitrile ( $\mathrm{ACN})$, or methanol $(\mathrm{MeOH})$. Each of the nine extracted fractions from their respective time interval, were taken to dryness and derivatized with BSTFA to a final volume as shown in Table 1. The quantity of BSTFA added (measured in $\mu$ ) was determined by the viscosity of the extract residue. The GC/MS conditions remained constant during the week long experiment. As before, a $2.0 \mu \mathrm{l}$ aliquot from each derivatized extract was injected into the gas chromatograph. Table 1 shows the area counts for each compound. It should be noted that the BSTFA dilution factor (as shown) for some extracts is twice that for others. This is due to viscous sediment residues.

\begin{tabular}{|l|l|l|l|l|l|l|l|l|}
\hline Substrate & $\begin{array}{l}\text { Round } \\
\text { Robin \# }\end{array}$ & $\begin{array}{l}\text { Time } \\
(\mathrm{hrs})\end{array}$ & $\begin{array}{l}\text { BSTFA } \\
(\mu \mathrm{l})\end{array}$ & $\begin{array}{l}\text { Extraction } \\
\text { Solvent }\end{array}$ & \multicolumn{4}{|l|}{$\begin{array}{l}\text { Peak Area (counts } \times 10^{6} \text { ) for a } 2 \mu \mathrm{l} \\
\text { Injection }\end{array}$} \\
\hline & & & & & MFA & DIPAE & $3-\mathrm{Q}$ & BA \\
\hline & 14 & 24 & 100 & ACN & 0.22 & 0.14 & - & 0.72 \\
\hline Acidic & 20 & 48 & 200 & $\mathrm{MeOH}$ & - & 0.35 & - & - \\
\hline & 25 & 96 & 100 & $3: 1$ & - & - & - & - \\
\hline & 15 & 24 & 200 & $\mathrm{ACN}$ & 0.03 & 0.30 & - & 0.13 \\
\hline Basic & 19 & 48 & 100 & $\mathrm{MeOH}$ & 0.04 & 0.22 & - & 2.60 \\
\hline & 19 & 72 & 100 & $\mathrm{MeOH}$ & 0.08 & 0.17 & - & 3.70 \\
\hline & 21 & 96 & 100 & $3: 1$ & - & - & - & - \\
\hline & 16 & 24 & 200 & $\mathrm{ACN}$ & 0.05 & 0.08 & - & 0.09 \\
\hline Neutral & 18 & 24 & 100 & $\mathrm{MeOH}$ & 0.04 & 1.10 & - & 0.06 \\
\hline & 22 & 24 & 100 & $3: 1$ & - & - & - & - \\
\hline
\end{tabular}

TABLE 1. Extraction solvent and aging study. 
It was evident from the data in Table 1 , that $\mathrm{ACN}$ was the most efficient extraction solvent of the three investigated. It is followed by $\mathrm{MeOH}$ with the least efficient being 3:1(isopropyl alcohol/methylene chloride). It should also be noted that the 3-Q was still only observed at trace levels in the extracts. Therefore, a new spiking solution was made up increasing the concentration of 3-Q by two fold while the concentrations of MPA, DIPAE, and BA remained the same as previously described.

4.) It was not readily evident from the above experiment whether the $\mathrm{MeOH}$ or $\mathrm{ACN}$ solvent system was best suited to extract the 3-Q. Therefore, both were employed for the next series of extraction experiments.

To three sets of soil substrates, weighing 50 grams each, was added a $1.0 \mathrm{ml}$ aliquot of the new spiking solution. This resulted in a concentration of $1 \mu \mathrm{g}$ of MPA, DIPAE, and BA per gram of soil, and $2 \mu \mathrm{g}$ of $3-\mathrm{Q}$ per gram of soil. Two sets of 10.0 gram quantities from each of the three substrates were extracted 24 hours later with their respective solvent mixture. Each of the six extracted fractions were taken to dryness and derivatized with BSTFA as shown in Table 2.

\begin{tabular}{|c|c|c|c|c|c|c|c|c|}
\hline \multirow[t]{2}{*}{ Substrate } & \multirow{2}{*}{$\begin{array}{l}\text { Round } \\
\text { Robin \# }\end{array}$} & \multirow{2}{*}{$\begin{array}{l}\text { Time } \\
\text { (hrs.) }\end{array}$} & \multirow{2}{*}{$\begin{array}{l}\text { BSTFA } \\
(\mu \mathrm{l})\end{array}$} & \multirow{2}{*}{$\begin{array}{l}\text { Extraction } \\
\text { Solvent }\end{array}$} & \multicolumn{4}{|c|}{$\begin{array}{l}\text { Peak Area (counts } \times 10^{6} \text { ) for a } 2 \mu l \\
\text { Injection }\end{array}$} \\
\hline & & & & & MPA & DIPAE & $3-Q$ & $\mathrm{BA}$ \\
\hline Acidic & $\begin{array}{l}26 \\
29 \\
\end{array}$ & $\begin{array}{l}24 \\
24 \\
\end{array}$ & $\begin{array}{l}100 \\
200\end{array}$ & $\begin{array}{l}\mathrm{ACN} \\
\mathrm{MeOH}\end{array}$ & $\begin{array}{l}0.12 \\
2.10\end{array}$ & $\begin{array}{l}0.39 \\
0.05\end{array}$ & - & $\begin{array}{l}0.37 \\
0.11\end{array}$ \\
\hline Basic & $\begin{array}{l}28 \\
31 \\
\end{array}$ & $\begin{array}{l}24 \\
24\end{array}$ & $\begin{array}{l}100 \\
100\end{array}$ & $\begin{array}{l}\mathrm{ACN} \\
\mathrm{MeOH}\end{array}$ & $\begin{array}{l}0.03 \\
-\end{array}$ & $\begin{array}{l}0.50 \\
-\end{array}$ & - & 0.17 \\
\hline Neutral & $\begin{array}{l}27 \\
30\end{array}$ & $\begin{array}{l}24 \\
24\end{array}$ & $\begin{array}{l}100 \\
100\end{array}$ & $\begin{array}{l}\mathrm{ACN} \\
\mathrm{MeOH}\end{array}$ & $\begin{array}{l}0.03 \\
-\end{array}$ & $\geq 0.01$ & - & $\begin{array}{l}0.21 \\
1.60\end{array}$ \\
\hline
\end{tabular}

TABLE 2. Extraction study of two different solvent systems.

The data in Table 2 show both solvents to be similarly though only moderately effective for extracting the target compounds. The major difference lying with the neutral soil, where, methanol was more efficient for benzilic acid and the acidic soil where, again, methanol extracted a greater amount of MPA. However acetonitrile seemed to extract detectable amounts of more compounds from more substrates. The table also shows that 3-Q was again not detected. The compound was either not extractable with the solvents under study or, the compound had decomposed on the soil substrates leaving no identifiable trace residues. Results of the routine analyses of the spiking solutions themselves did not show evidence of decomposition.

5.) A new series of experiments was begun by spiking $50 \mathrm{~g}$ soil samples and dividing them into $25 \mathrm{~g}$ portions. Each portion was first extracted with $\mathrm{ACN}$ followed by a water extraction. A non-spiked soil substrate was also extracted with ACN and water. Spiking standards were in the analysis for quantification purposes. These were from the same stock solution used to spike the soils and were prepared at concentrations that would bracket the expected concentration levels of samples. These standards were placed at the 
beginning and end of each GC/MS analysis run of the unknown samples to follow the GC/MS response over the entire batch of runs.

The $A C N$ and the water extracts from the soil substrates were evaporated to dryness, and then derivatized with $100 \mu$ l of BSTFA. A $2.0 \mu$ l aliquot from the derivatized extract was injected into the GC-MS instrument. Only about half of the samples were successfully injected into the GC-MS instrument. Problems were encountered due to samples being either quite viscous and/or still containing sediments after the centrifugation process. Table 3 lists the area counts for each of the compounds extracted from the three soil substrates. It can be seen from Table 3 that both the solvent and water extracts from basic soil gave poor results. The DIPAE was not extracted by $\mathrm{ACN}$ and none of the compounds were detected from the subsequent water extraction. Along with a strong interaction with the basic soil, we speculated that the ultrasonication and centrifugation processing times for the soil substrates might also be an important factor. With longer sonication times there is a likelihood of increased fracture of soil particles resulting in higher surface areas and more active sites. This would result in a greater affinity for target analytes.

\begin{tabular}{|l|l|l|l|l|l|l|}
\hline Compound & \multicolumn{6}{l|}{ Peak Area (counts $\times 10^{5}$ ) for a $2 \mu$ Injection } \\
\hline & $\mathrm{H}_{2} \mathrm{O}-\mathrm{B}$ Fractions & ACN-A Fractions \\
\hline & SN & SB & SA & SN & SB & SA \\
\hline MPA & 0.49 & - & 0.33 & 0.22 & 0.29 & 0.54 \\
\hline DIPAE & 0.95 & - & 3.60 & 0.35 & - & 0.44 \\
\hline 3-Q & - & - & - & - & - & - \\
\hline BA & 1.4 & - & 1.70 & $\geq 0.01$ & 0.04 & 0.01 \\
\hline
\end{tabular}

TABLE 3. Analysis of water (post-solvent extraction) and solvent fractions.

6.) A second set of neutral and acidic ( $\mathrm{pH} \mathrm{2.0)}$ aqueous extractions were carried out with each soil substrate. A $10 \mathrm{~g}$ sample was used for each extraction. This was primarily to test for an improvement in the DIPAE extraction from basic soil. As before, the standards were made from the same stock solution used to spike the soils and were prepared at concentrations that would bracket the expected concentration levels of samples. Again these standards were placed at the beginning and end of each GC/MS analysis run. The results of both the neutral and acidic aqueous extractions are shown in Table 4. The improved recovery of DIPAE is obvious for both the acidic and neutral $\mathrm{pH}$ fractions when compared to the basic soil results in Table 3. However, it is emphasized here that the data from the aqueous extractions listed in Table 4 were not obtained by the same procedure as those listed in Table 3 as the aqueous extractions listed in Table 3 were subsequent to an $\mathrm{ACN}$ extraction.

7.) A final set of experiments was aimed specifically at efficient extraction of $3-Q$ and DIPAE from soils. Since these compounds are basic in nature, we chose an acidic extraction procedure; i.e., $1 \mathrm{~N}$ aqueous $\mathrm{HCl}$. The $\mathrm{pH}$ of the extract was then adjusted to 11 or 12 by addition of base. The basic aqueous solution of the analytes was then extracted with a 3:1 solvent mixture (isopropyl alcohol / methylene chloride). These extracts from the three soil substrates were evaporated to dryness and derivatized with $100 \mu$ of 
the three soil substrates were evaporated to dryness and derivatized with $100 \mu \mathrm{l}$ of BSTFA. A $2.0 \mu \mathrm{l}$ aliquot from the derivatized extract was injected into the gas chromatograph. An example of a resulting TIC is given in Figure 6. Both 3-Q and DIPAE were readily detected in all three soil substrates.

\begin{tabular}{|l|l|l|l|l|l|l|}
\hline Compound & \multicolumn{6}{|l|}{ Peak Area (counts $\times 10^{5}$ ) for a $2 \mu$ Injection } \\
\hline & $\mathrm{SB}-\mathrm{H}_{2} \mathrm{O}$ & $\mathrm{SB}-\mathrm{HCl}$ & $\mathrm{SN}-\mathrm{H}_{2} \mathrm{O}$ & $\mathrm{SN}-\mathrm{HCl}$ & SA- $\mathrm{H}_{2} \mathrm{O}$ & SA-HCl \\
\hline MPA & 0.16 & 0.02 & 0.40 & 0.01 & - & - \\
\hline DIPAE & 1.10 & 0.42 & - & 0.56 & - & 0.01 \\
\hline $3-\mathrm{Q}$ & - & - & - & - & - & - \\
\hline BA & 3.40 & 0.10 & 1.70 & 0.13 & 0.01 & 0.02 \\
\hline
\end{tabular}

TABLE 4. Neutral (pH 7.0) and acidic ( $\mathrm{pH} 2.0)$ extractions.

The results of this work demonstrated that, although the extraction of polar compounds from soil is difficult, a sequential extraction procedure using an organic solvent followed by aqueous acid was effective for the compounds selected for Round Robin 4.

Extraction Experiments--Water:

The same extraction procedure was used on both the water sample itself and on the aqueous eluent from the $\mathrm{C}-18$ solid phase extractant cartridge. Fifty ml volumes of sample were extracted with the $3: 1$ solvent mixture (methylene chloride/isopropyl alcohol). These extracts from both samples and the aqueous phase from both of the extractions were evaporated to dryness under helium purge. All four samples were then derivatized with $100 \mu \mathrm{l}$ of BSTFA. A $2.0 \mu \mathrm{l}$ aliquot from each were injected into the GCMS instrument. The results are shown in Table 5.

\begin{tabular}{|l|l|l|l|l|}
\hline Compound & \multicolumn{4}{|c|}{ Peak Area (counts $\times 10^{6}$ ) } \\
\hline & $\begin{array}{l}\text { Eluent } \\
\text { Water }\end{array}$ & $\begin{array}{l}\text { Eluent } \\
\text { Water }\end{array}$ & $\begin{array}{l}\text { Water } \\
\text { Sample }\end{array}$ & $\begin{array}{l}\text { Water } \\
\text { Sample }\end{array}$ \\
\hline & Extract & $\begin{array}{l}\text { Aqueous } \\
\text { Phase }\end{array}$ & Extract & $\begin{array}{l}\text { Aqueous } \\
\text { Phase }\end{array}$ \\
\hline MPA & 0.01 & 0.21 & 0.01 & - \\
\hline DIPAE & 0.04 & - & 0.09 & - \\
\hline 3-Q & 0.81 & 1.70 & 1.20 & - \\
\hline BA & 0.67 & 1.10 & 1.20 & - \\
\hline
\end{tabular}

TABLE 5. Water samples and cartridge eluent.

The GC/MS data from the 3:1 extractions show all compounds were readily detected pre- and post-C-18 cartridge. The chromatograms of the evaporated aqueous phase showed that the extractions were not $100 \%$ efficient. 


\section{Extraction Experiments--Cartridge}

The C-18 cartridge was chosen by the Round Robin 4 participants because of its capability of extracting hydrocarbons from aqueous solution. The cartridge is quite effective and is primarily used for efficiently extracting non-polar compounds from aqueous solution. However, the four compounds chosen for spiking ranged from relatively polar to very polar. Therefore, the need to determine the extraction capabilities of the $\mathrm{C}-18$ cartridge for the compounds as a pre-exercise experiment was necessary.

A sample of the water to be used in the exercise $(50 \mathrm{ml})$ containing the spike compounds was passed through a preconditioned cartridge containing one gram of $\mathrm{C}-18$ packing. Assuming $100 \%$ extraction efficiency for the $\mathrm{C}-18$ packing, a final concentration of $500 \mu \mathrm{g}$ of MPA, DIPAE, and BA per gram of packing, and $1000 \mu \mathrm{g}$ of 3-Q per gram of packing would be obtained. The stripping of the compounds from the cartridge polymer was accomplished by passing three $10 \mathrm{ml}$ volumes of ACN through the cartridge, evaporating the eluents to dryness and derivatizing with $100 \mu$ l of BSTFA. A $2.0 \mu \mathrm{l}$ aliquot from the derivatized extract was injected into the gas chromatograph (See Fig. 7). To monitor the efficiency of the solid phase extraction tube and the extraction solvent, a $1.0 \mathrm{ml}$ aliquot of the spiking solution was dried directly under helium purge and derivatized with $100 \mu \mathrm{l}$ of BSTFA. Therefore, the concentrations from the ACN extraction would, theoretically, be the same as the standard. As before, a $2.0 \mu \mathrm{l}$ aliquot from the derivatized standard was injected into the GC-MS (See Figure 8).

A $1 \mathrm{ml}$ aliquot of the eluent water from the cartridge was evaporated to dryness and derivatized with $100 \mu \mathrm{l}$ of BSTFA. A $2.0 \mu \mathrm{l}$ aliquot from the derivatized extract was injected into the GC-MS (See Figure 9). If none of the compounds were retained on the cartridge, their concentrations in the $1 \mathrm{ml}$ aliquot would theoretically be $1 / 50$ of the standard. A $1.0 \mathrm{ml}$ aliquot of this standard was dried under helium purge and derivatized with $100 \mu \mathrm{l}$ of BSTFA. Again, a $2.0 \mu \mathrm{l}$ aliquot from the derivatized standard was injected into the gas chromatograph (See Figure 10).

\begin{tabular}{|l|c|c|}
\hline Compound & \multicolumn{2}{|c|}{ Peak Area $\left(\times 10^{7}\right)$ for a $2 \mu$ Injection } \\
\hline & Figure 6 & Figure 7 \\
\hline MPA & 5.63 & $\geq 0.01$ \\
\hline DIPAE & 2.72 & 1.63 \\
\hline 3-Q & 6.88 & 0.36 \\
\hline BA-1 & 0.36 & - \\
\hline BA-2 & 2.21 & 0.07 \\
\hline
\end{tabular}

TABLE 6. Standard compared to C-18 extract.

Table 6 lists the counts for each compound from Figures $7 \& 8$ and Table 7 lists the counts for each compound from Figures $9 \& 10$. An additional $\mathrm{ml}$ of the eluent water was extracted and analyzed one week later. The results shown in Figure 11 and Table 7 show that no appreciable decomposition occurs during that time period. 


\begin{tabular}{|l|c|c|c|}
\hline Compound & \multicolumn{3}{|c|}{ Peak Area (counts $\times 10^{6}$ ) for a 2 $\mu$ I Injection } \\
\hline & Eluent & Standard & $\begin{array}{l}\text { Eluent }+1 \\
\text { week }\end{array}$ \\
\hline MPA & 0.03 & 0.05 & 0.02 \\
\hline DIPAE & 0.17 & 1.14 & 0.15 \\
\hline 3-Q & 0.23 & 0.99 & 0.22 \\
\hline BA-1 & - & - & - \\
\hline BA-2 & 0.09 & 0.14 & $\geq 0.10$ \\
\hline
\end{tabular}

TABLE 7. Cartridge eluent, standard, and 1 week aged eluent.

A final set of extraction experiments was performed using a C-18 cartridge prepared as described above. Three $2 \mathrm{ml} \mathrm{ACN}$ washes were passed through the cartridge, collected, dried, and derivatized. Next, three $2 \mathrm{ml}$ portions of 3:1 (isopropyl alcohol/methylene chloride), were passed through the cartridge, collected, dried, and derivatized. The results of the GC/MS analysis of the extracts are shown in Table 8. This was followed by a procedure similar to that used for the soil extractions; extraction with $1 \mathrm{~N} \mathrm{HCl}$, adjust the $\mathrm{pH}$ to $11-12$, extract with $3: 1$ (isopropyl alcohol/methylene chloride), evaporate to dryness, derivatize and analyze. The results of this procedure are also listed in Table 8. This final procedure proved to be the most effective for analyzing the compounds chosen for Round Robin 4.

\begin{tabular}{|l|l|l|l|}
\hline Compound & \multicolumn{3}{|l|}{ Peak Area $\left(\times 10^{6}\right)$ for a 2 $\mu$ I Injection } \\
\hline & $\begin{array}{l}\text { ACN } \\
\text { Extract }\end{array}$ & $\begin{array}{l}3: 1 \\
\text { Extract }\end{array}$ & $\begin{array}{l}\text { Acid } \\
\text { Extract }\end{array}$ \\
\hline MPA & - & - & 0.02 \\
\hline DIPAE & 0.13 & - & 0.12 \\
\hline 3-Q & - & - & 0.35 \\
\hline BA & 0.07 & - & 0.03 \\
\hline
\end{tabular}

TABLE 8. Sequential solvent extractions of the cartridge.

\section{Packaging and Shipping:}

All samples were packaged in "Quality Certified" glass containers from Environmental Sampling Supply (ESS), San Leandro, California. No additional treatment of the containers was done. Teflon liners were used in the lids of the clear glass soil containers while Teflon/silicone septa were used for the amber glass water sample containers. Primary containers were further wrapped to minimize the possibility of breakage.

The packages were labeled with a code consisting of two letters (sample blanks had a "B" as a third letter) indicating the type of sample substrate, followed by a number 
indicating the laboratory to which it was sent. Each participating laboratory received eleven (11) samples as follows:

$\begin{array}{ll}\text { SA-1 } & \text { Acid Soil - Spiked - Lab \#1 } \\ \text { SAB-1 } & \text { Acid Soil - Blank - Lab \#1 } \\ \text { SB-1 } & \text { Basic Soil - Spiked - Lab \#1 } \\ \text { SBB-1 } & \text { Basic Soil - Blank - Lab \#1 } \\ \text { SN-1 } & \text { Neutral Soil - Spiked - Lab \#1 } \\ \text { SNB-1 } & \text { Neutral Soil - Blank - Lab \#1 } \\ \text { W-1 } & \text { Water - Preserved w/ } \mathrm{CH}_{2} \mathrm{Cl}_{2} \text { and Spiked - Lab \#1 } \\ \text { WB-1 } & \text { Water - Blank - Preserved w/ } \mathrm{CH}_{2} \mathrm{Cl}_{2} \text { - Lab \#1 } \\ \text { K-1 } & \text { Loaded Cartridge - Lab \#1 } \\ \text { KB-1 } & \text { Cartridge - Blank - Lab \#1 } \\ \text { KEW-1 } & \text { Cartridge Eluent Water - Lab \#1 }\end{array}$

Shipping was done through commercial air freight.

The laboratories to which the samples were sent are listed in Attachment 1.

\section{Round Robin 4 Results Meeting:}

The meeting of the participants in the Round Robin 4 exercise was held at the Chemical and Biological Defence Establishment (CBDE), Porton Down, UK, during the week of 17 May 1993. All of the participants except for the Russians were represented. We made a presentation giving a summary of the procedures used to make up the samples.

All of the participants agreed that the exercise was a challenging one. Only four of the laboratories found all of the spiking compounds on all of the substrates. As expected, the soil samples presented the greatest challenge. The successful laboratories all used a sequential extraction procedure. However, in all cases, the organic extractant was different from the acetonitrile used here at LLNL, and the polar extractant was methanolic potassium hydroxide rather that the aqueous acid used here.

Since the exercise, we have explored basic extraction and agree that there may be some advantages with certain analytes on certain substrates. This work and additional work with solid phase extractant cartridges will be presented in a subsequent report.

The Round Robin participants agreed to the need to continue an international cooperative program such as this. However, it was the consensus that any such program should be brought under the auspices of the Preparatory Commission of the OPCW that is meeting in the Hague. Three topics for future exploration were suggested for presentation to the Prep Com:

1.) A continuation of $R R 4$ with all laboratories validating the same (optimized) extraction procedures,

2.) An experiment involving analyzing bodily fluids, and

3.) An exercise investigating on-site sample collection and analysis methods. These recommendations were presented to the Analytical Chemists Working Group at the Prep Com in its June meeting. 


\section{Summary:}

The Lawrence Livermore National Laboratory (LLNL) prepared samples to be analyzed by the international laboratories participating the Round Robin 4 . The samples consisted of four spiking compounds representing decomposition products of $\mathrm{CW}$ agents on three types of soil, in water and on a solid phase extraction cartridge. A series of characterization experiments were performed at LLNL. These experiments showed that while the extraction from the soils would not be straightforward, it could be accomplished by sequential extraction using non polar followed by very polar (acid or base) solvents.

The results of Round Robin 4 confirmed the difficulty of soil extractions and the need for further work in the area of analytical chemistry to support CWC inspections. 
FIGURES 
Figure 1. Total Ion Chromatogram of basic soil extract showing the naphthalene-d8 internal standard.

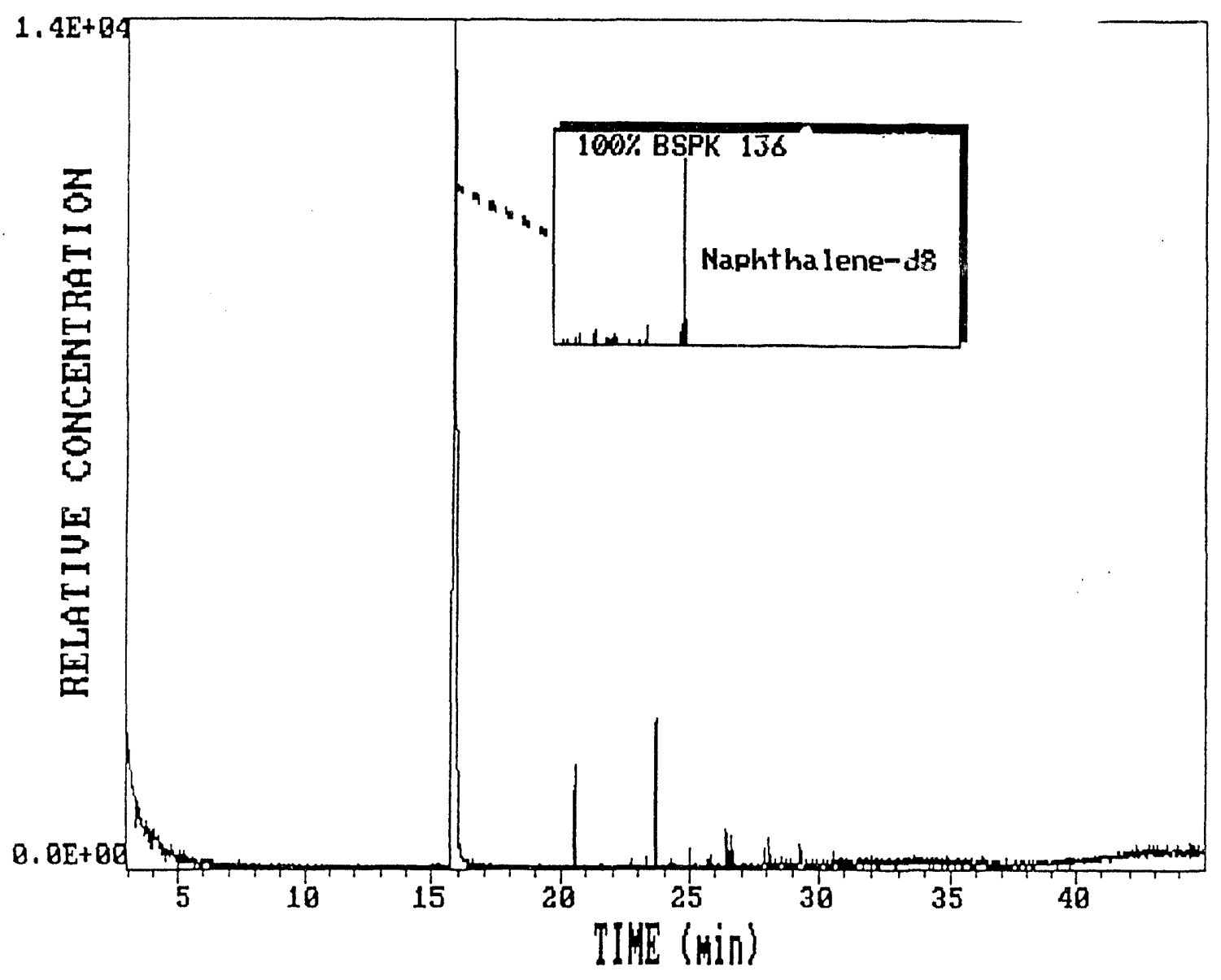


(UIW) 政LL

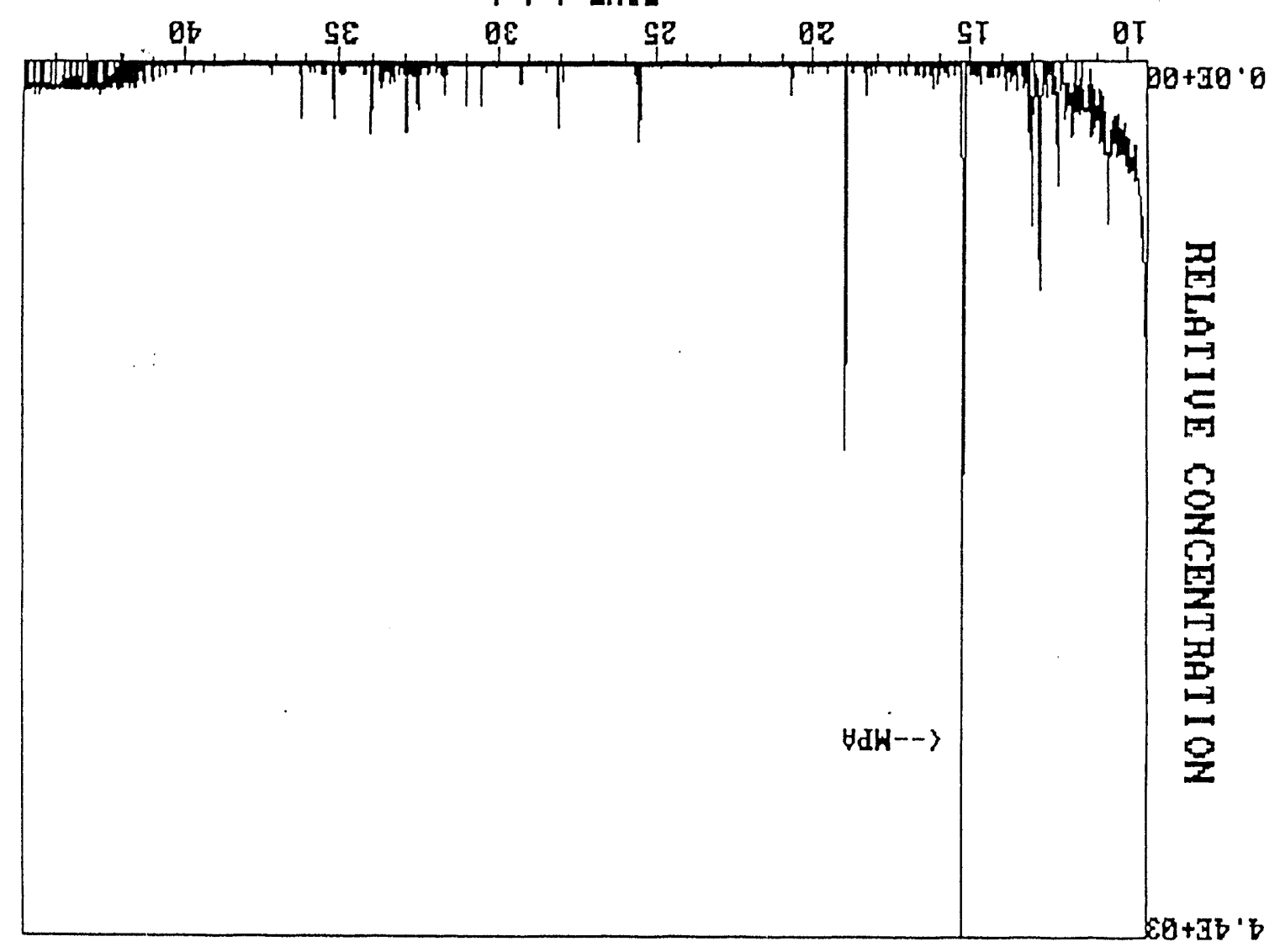

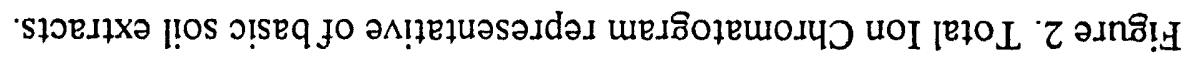




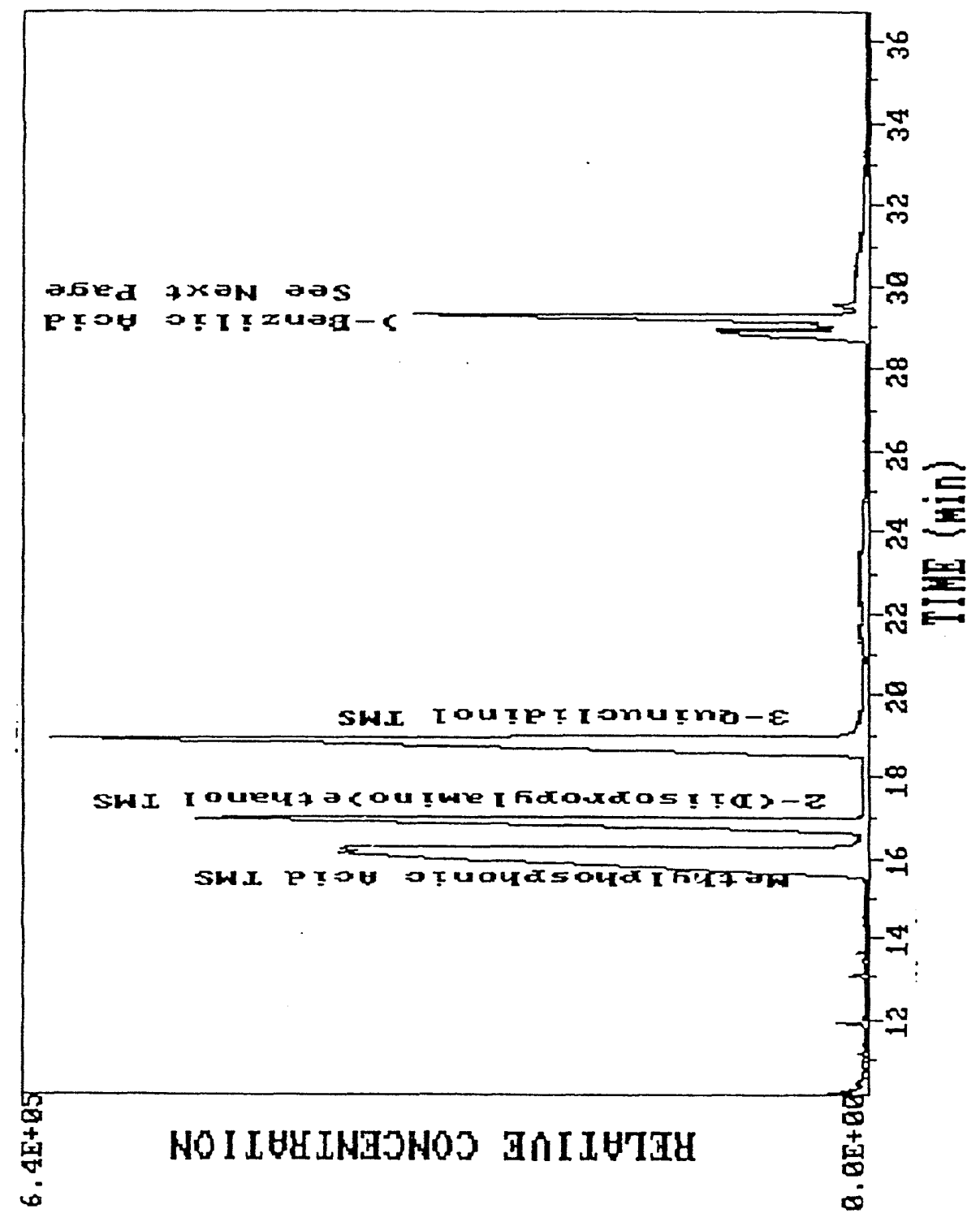


Figure 3b. Expanded Total Ion Chromatogram of derivatized spiking solution showing mono and di derivatization of benzilic acid

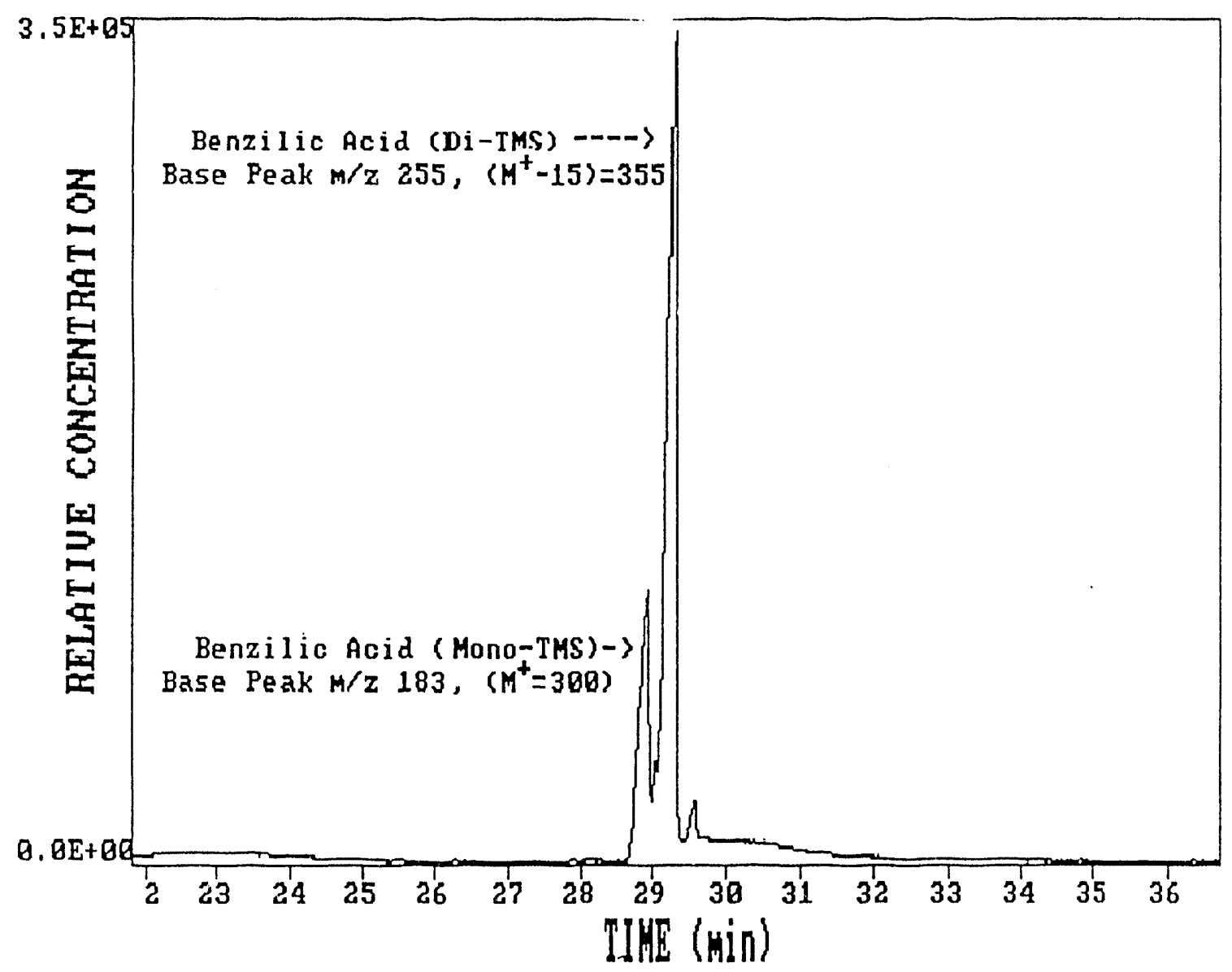


Figure 3c. Total Ion Chromatogram of derivatized spiking solution with mass spectrum of derivatized methylphosphonic acid (MPA)
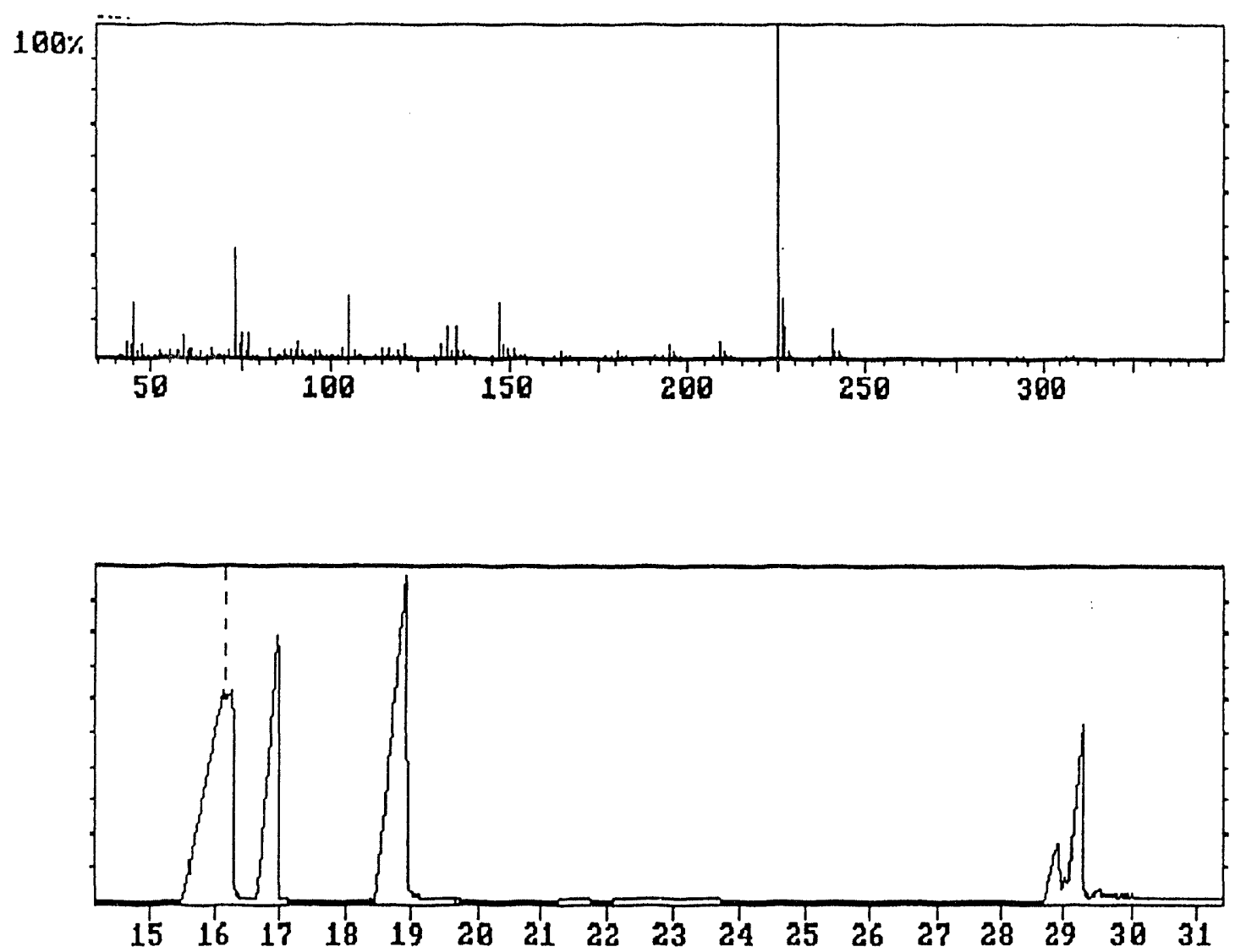
Figure 3d. Total Ion Chromatogram of derivatized spiking solution with mass spectrum of derivatized diisopropylamino ethanol (DIPAE).
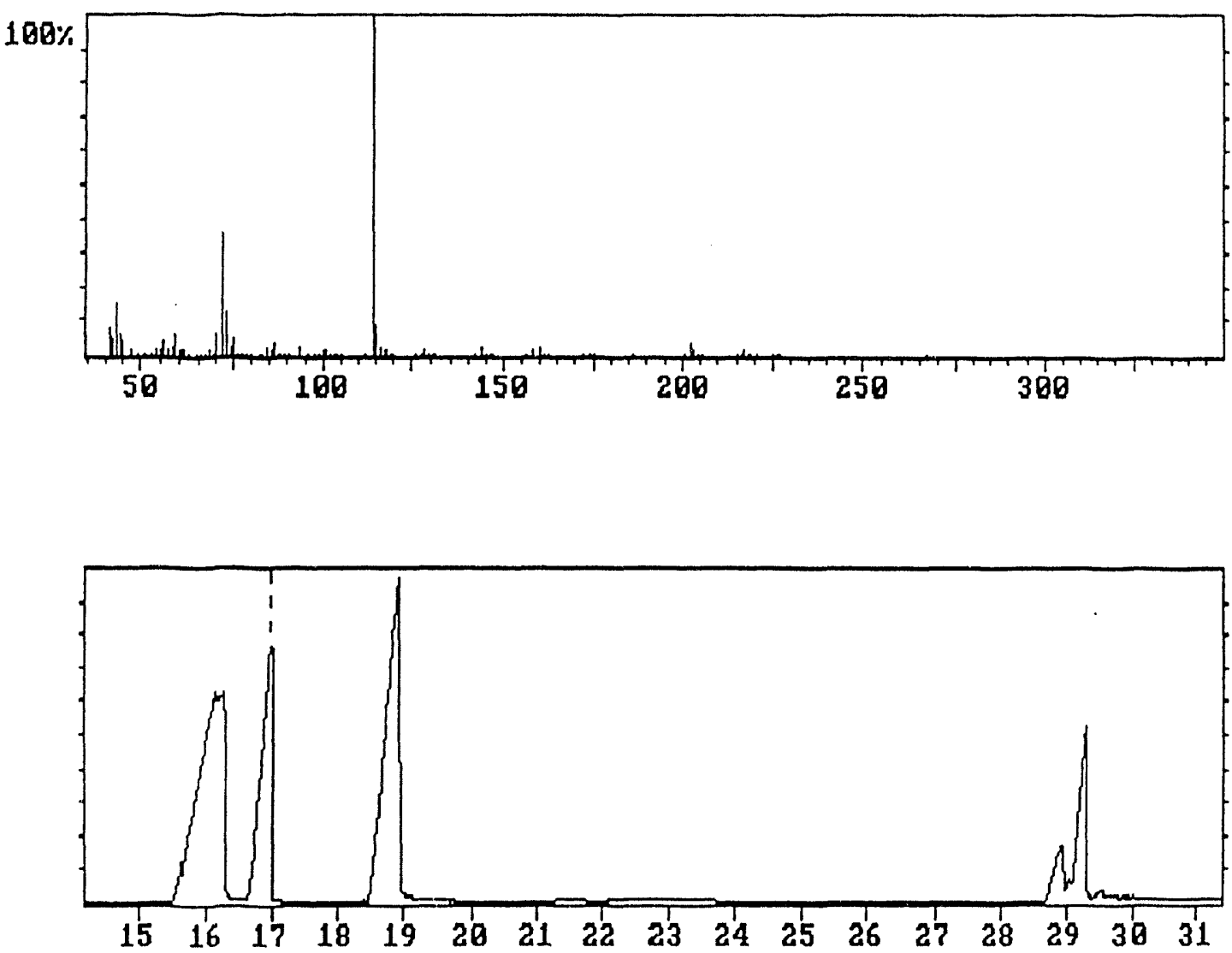
Figure 3e. Total Ion Chromatogram of derivatized spiking solution with mass spectrum of derivatized 3-quinuclidinol
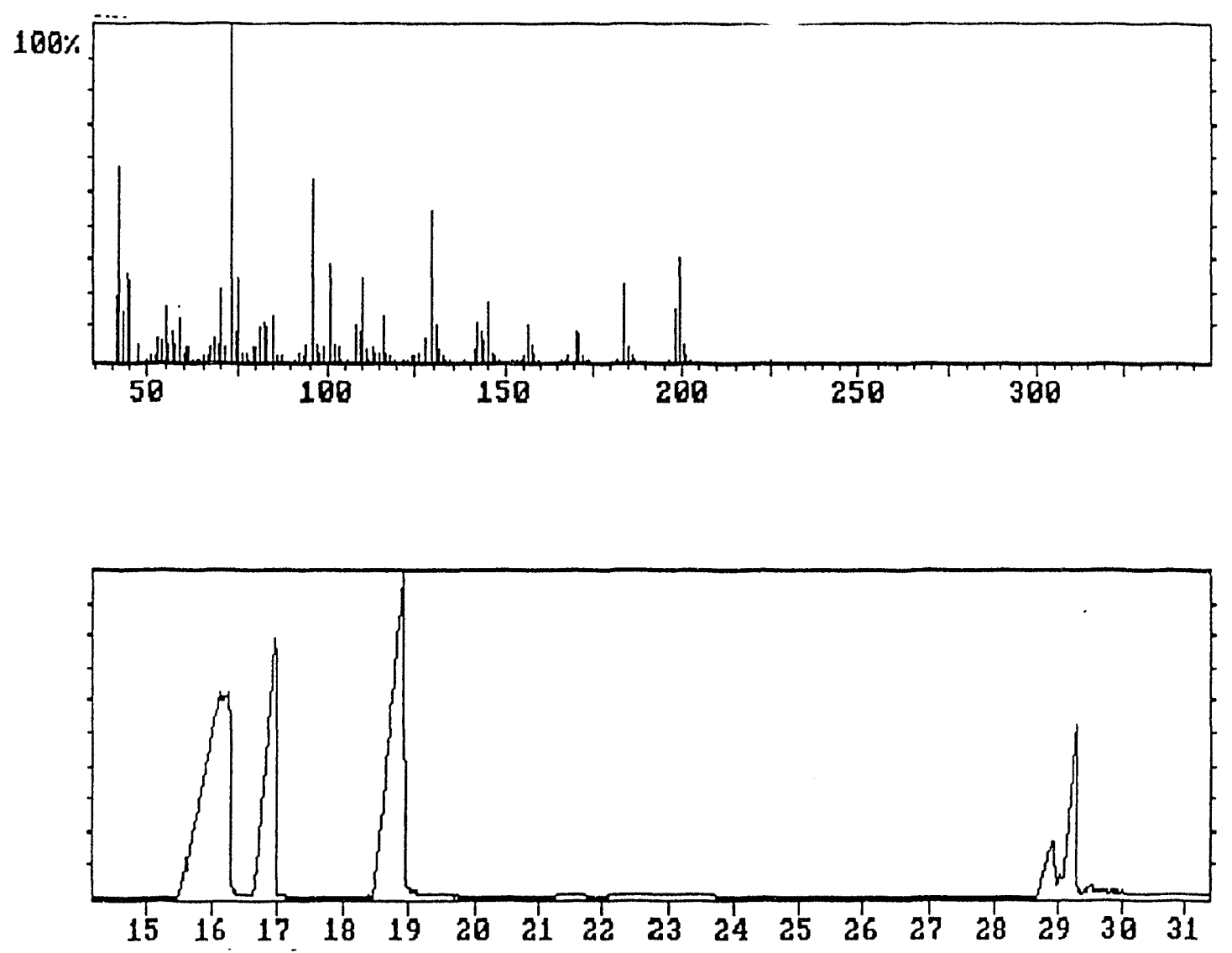
Figure 3f. Total Ion Chromatogram of derivatized spiking solution with mass spectrum of derivatized benzilic acid-mono TMS derivative.
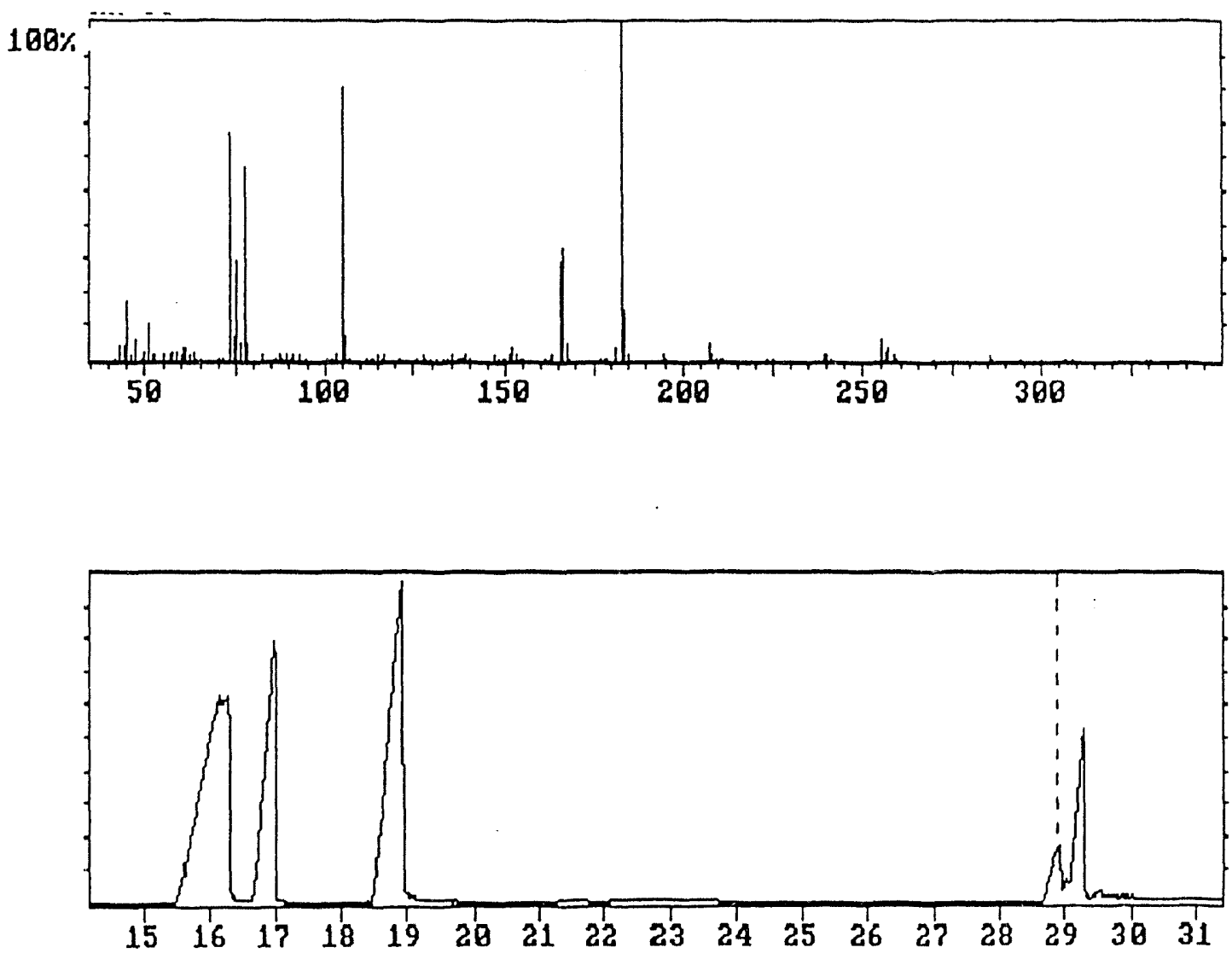

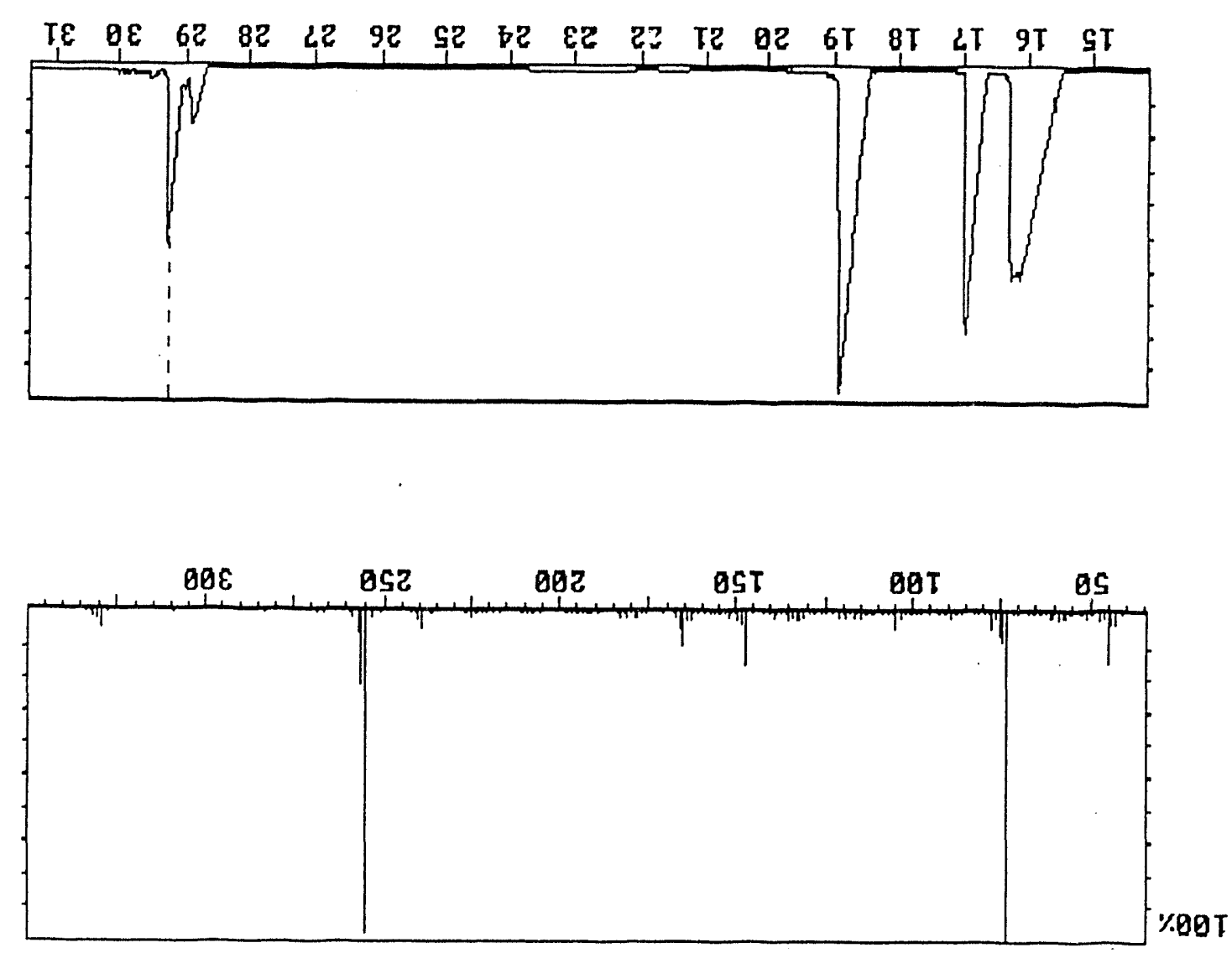

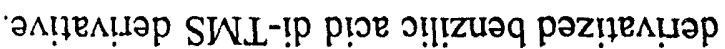

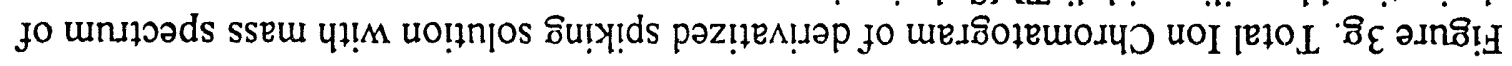


Figure 4. Total Ion Chromatogram of derivatized acetonitrile extract of soil spiked at a concentration of $10 \mu \mathrm{g}$ per gram.

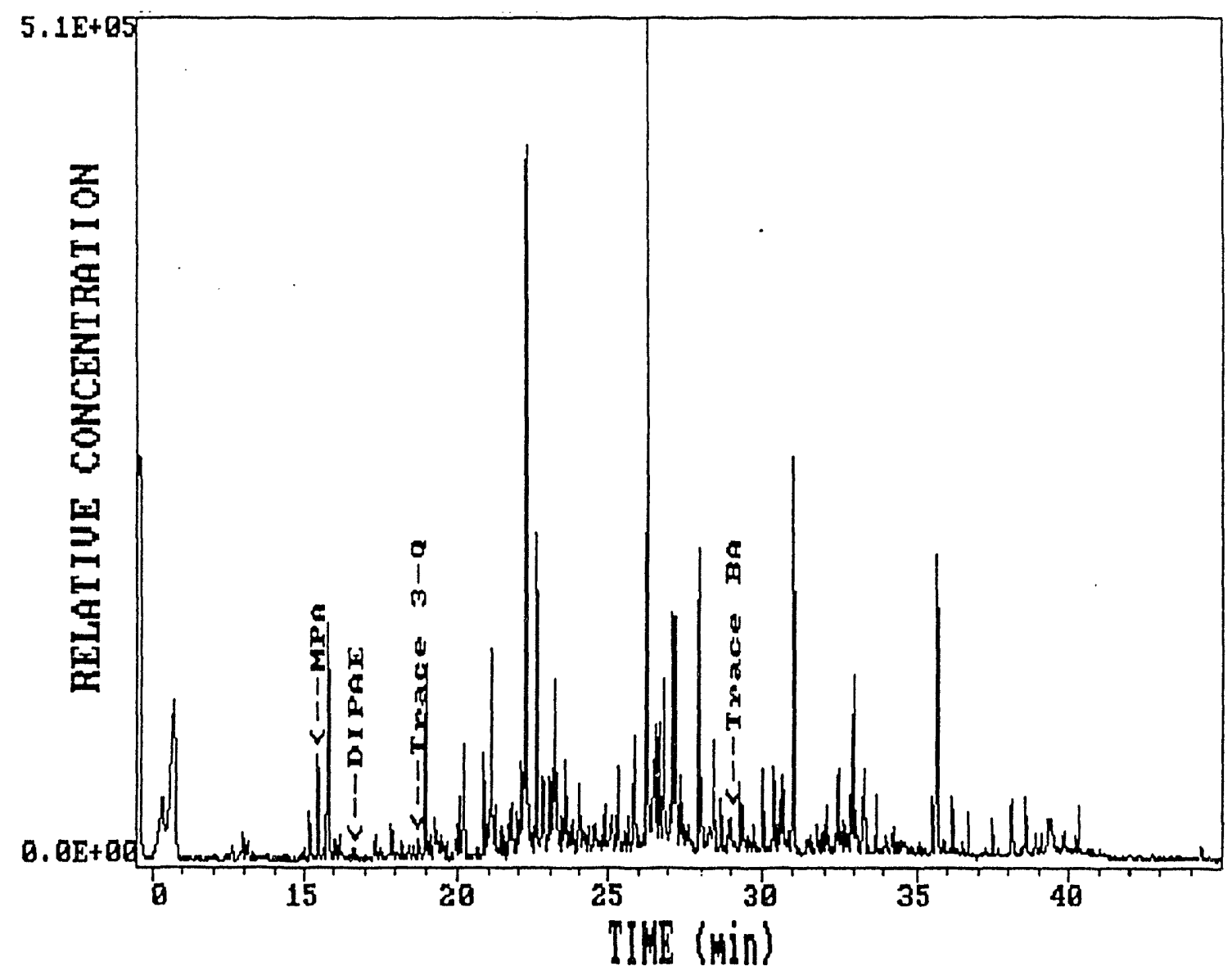


Figure 5. Total Ion Chromatogram of derivatized acetonitrile extract of soil spiked at a concentration of $100 \mu \mathrm{g}$ per gram.

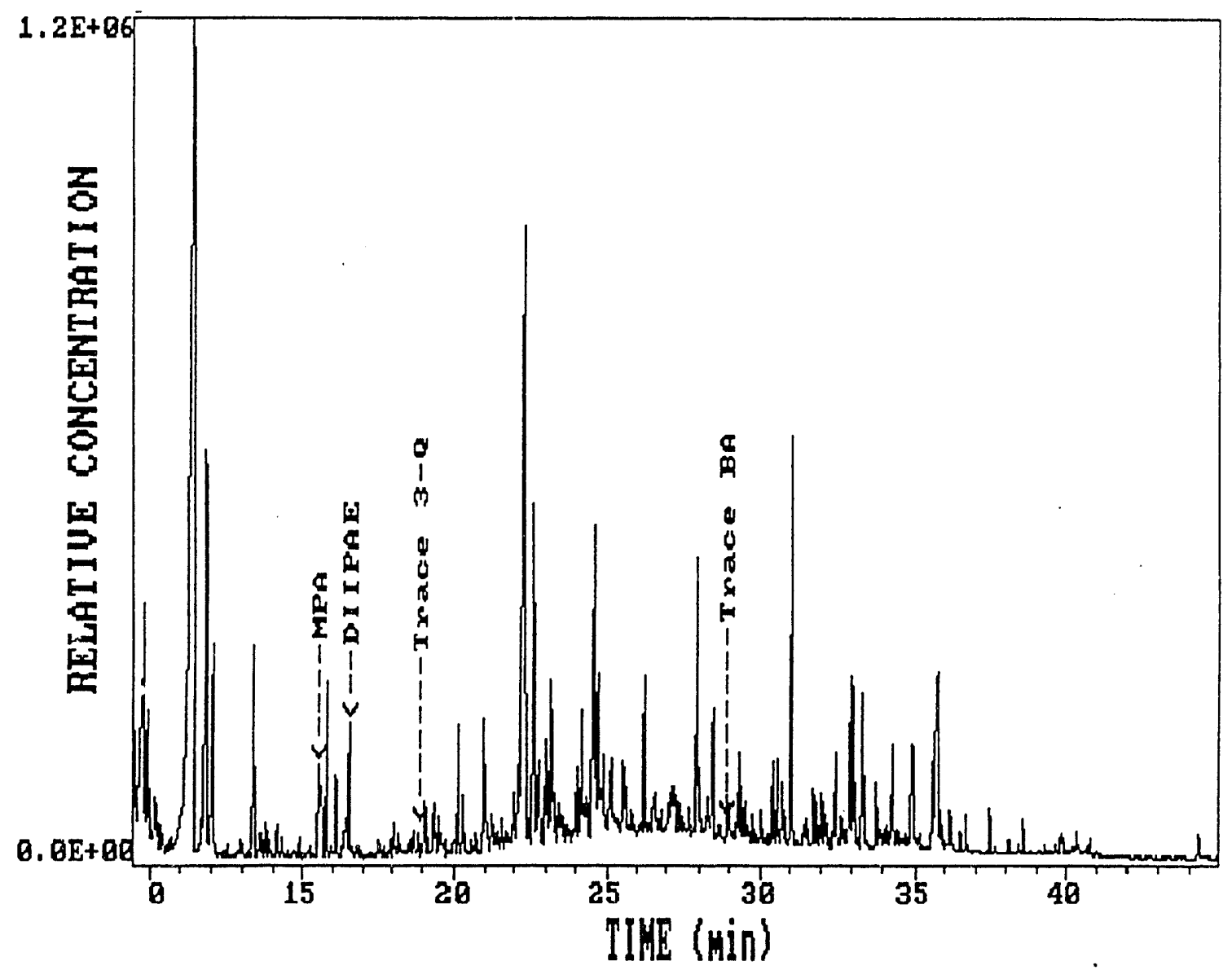


Figure 6. Total Ion Chromatogram of derivatized acid extract of neutral soil

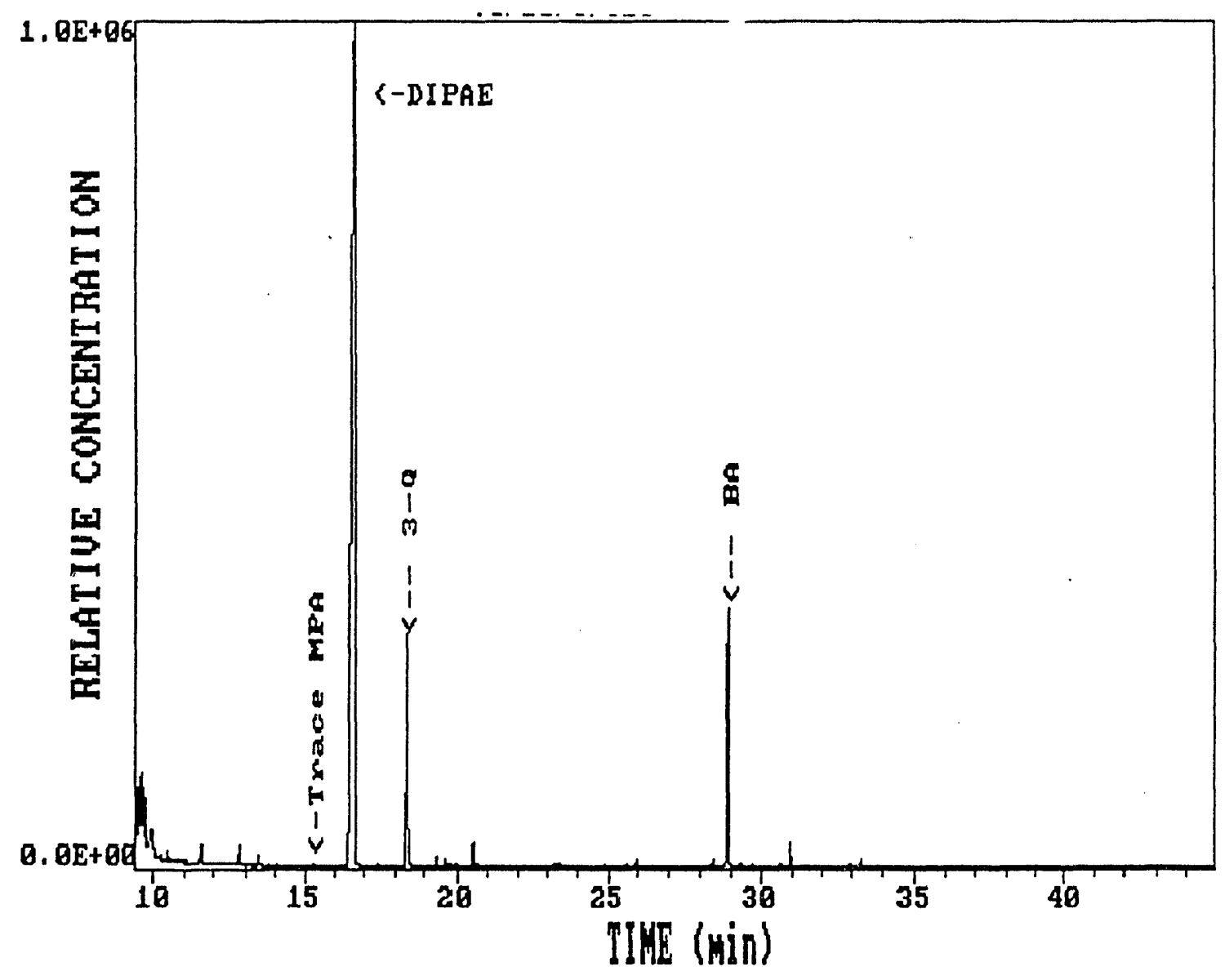


Figure 7. Total Ion Chromatogram of derivatized extract from C-18 cartridge

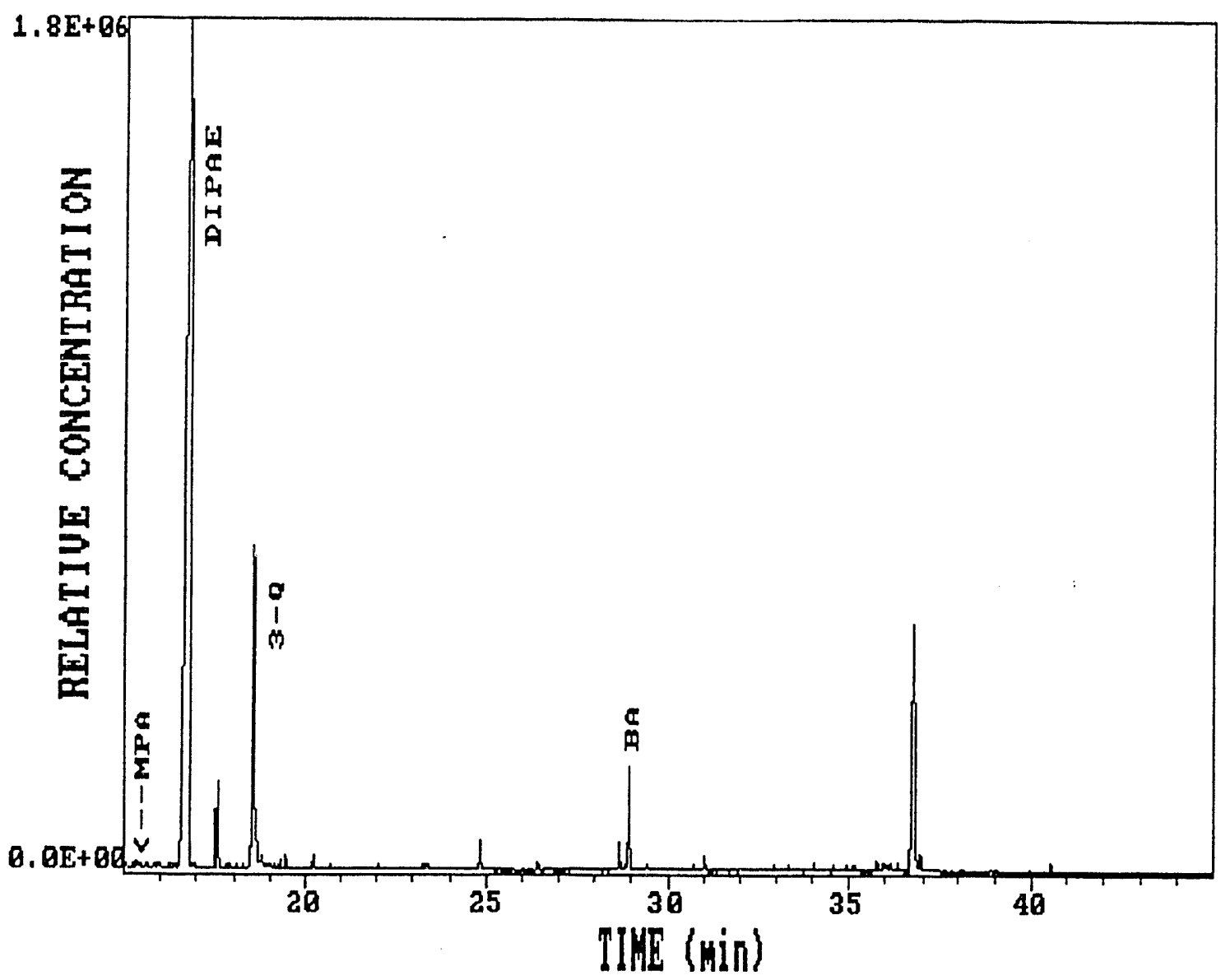


Figure 8. Total Ion Chromatogram of derivatized extract from spiking standard solution.

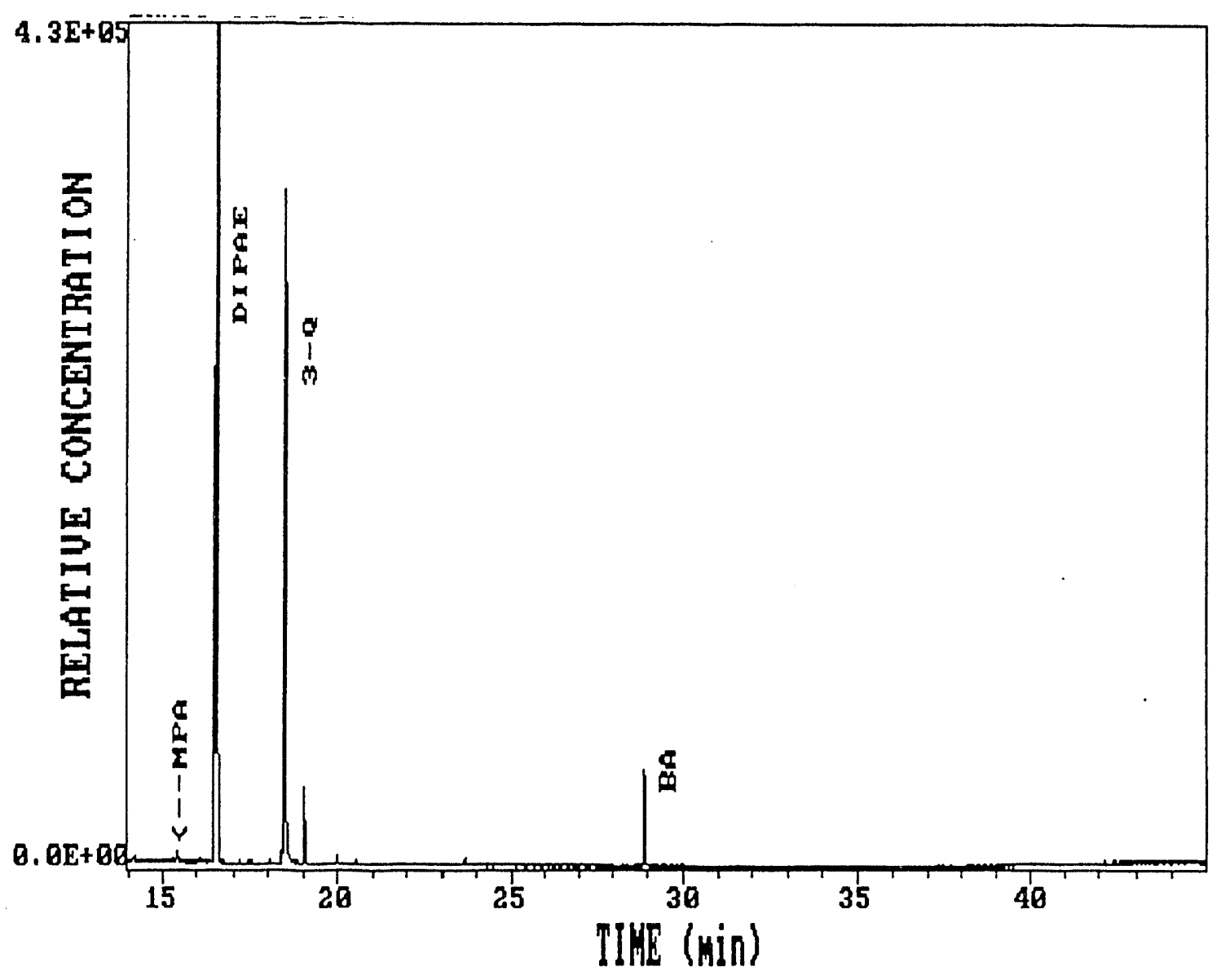


Figure 9. Total Ion Chromatogram of derivatized aqueous eluent from C-18 cartridge

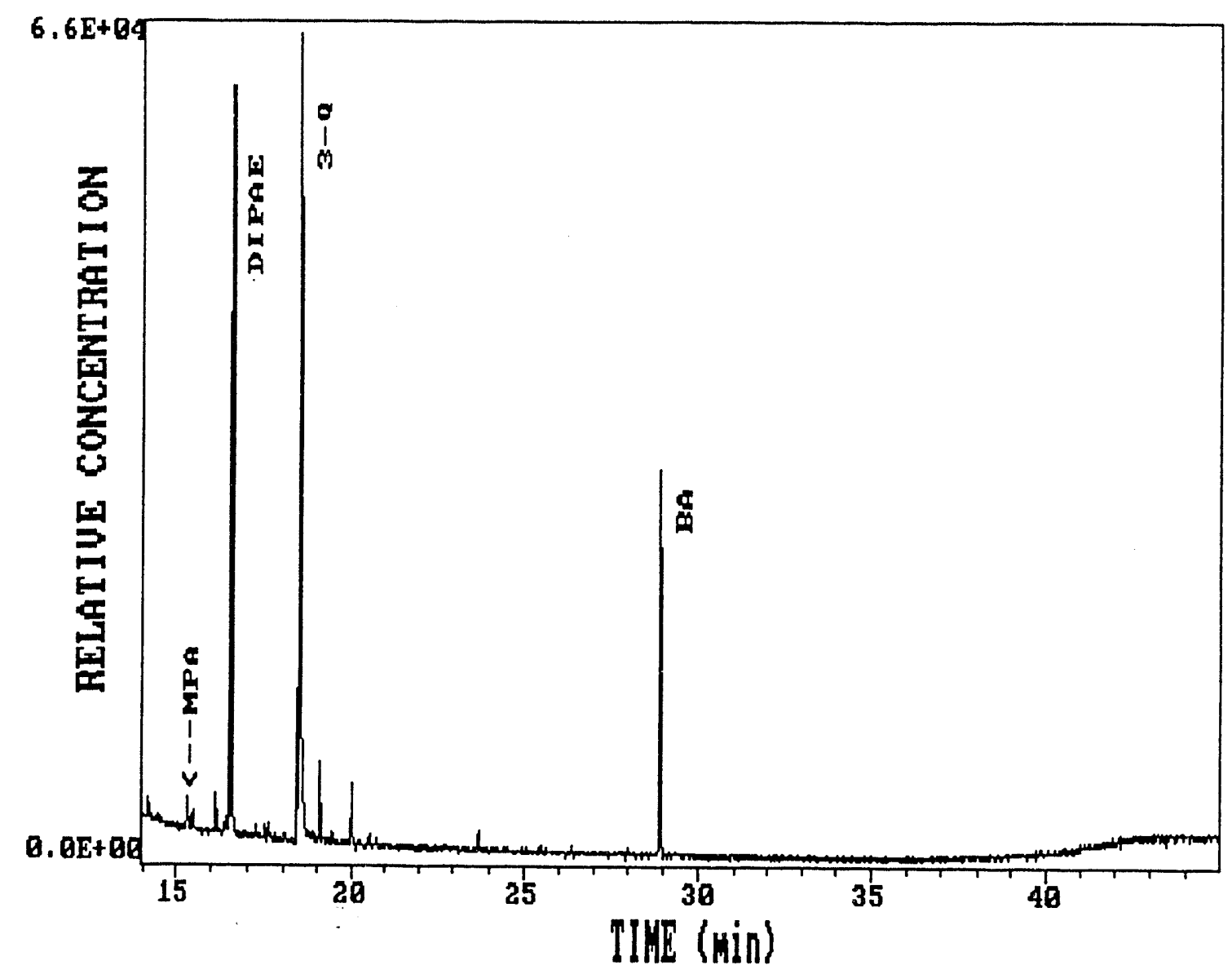


Figure 10. Total Ion Chromatogram of derivatized spiking solution used for $\mathrm{C}-18$ cartridge.

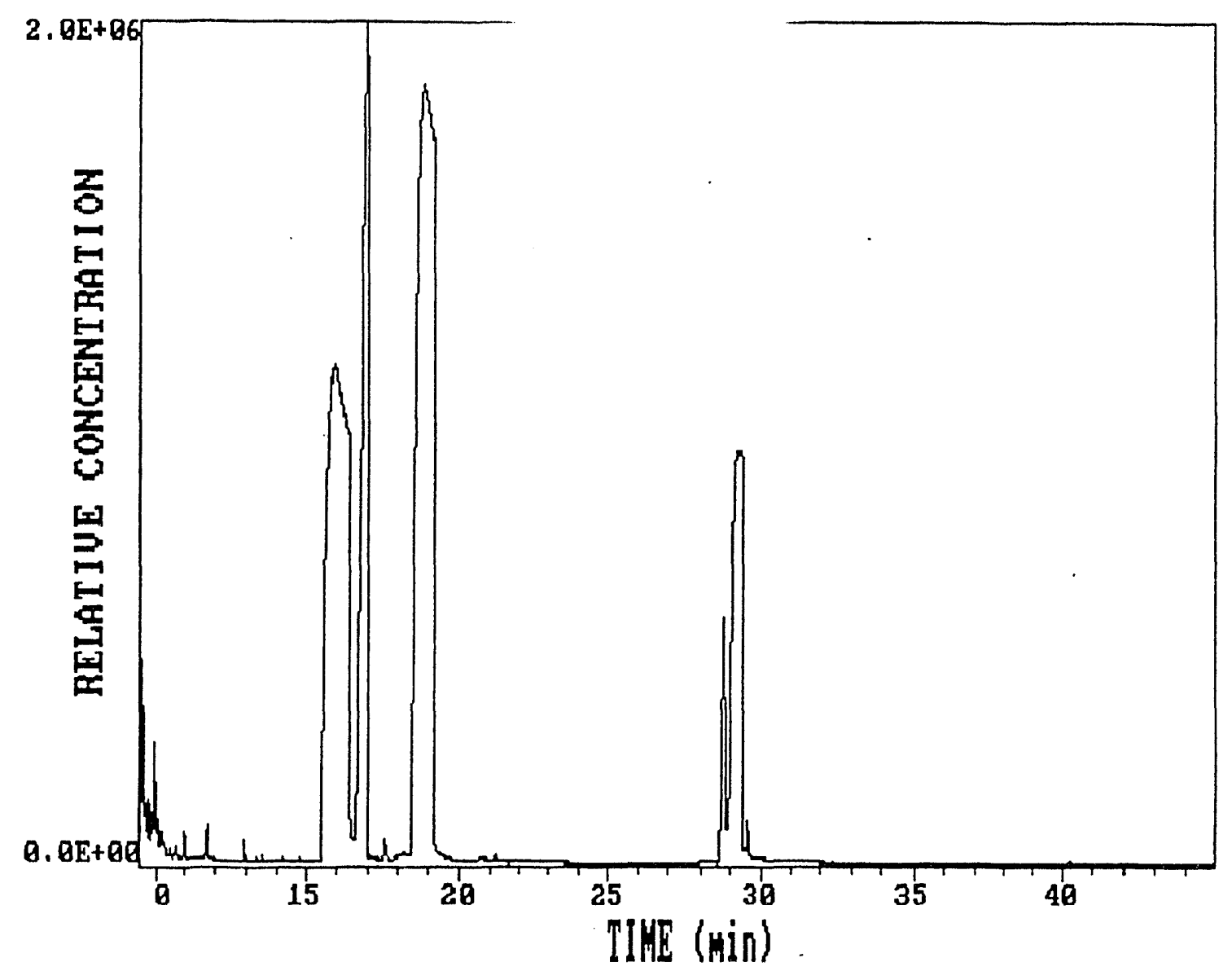


Figure 11. Total Ion Chromatogram of derivatized aqueous eluent from C-18 cartridge after 1 week storage.

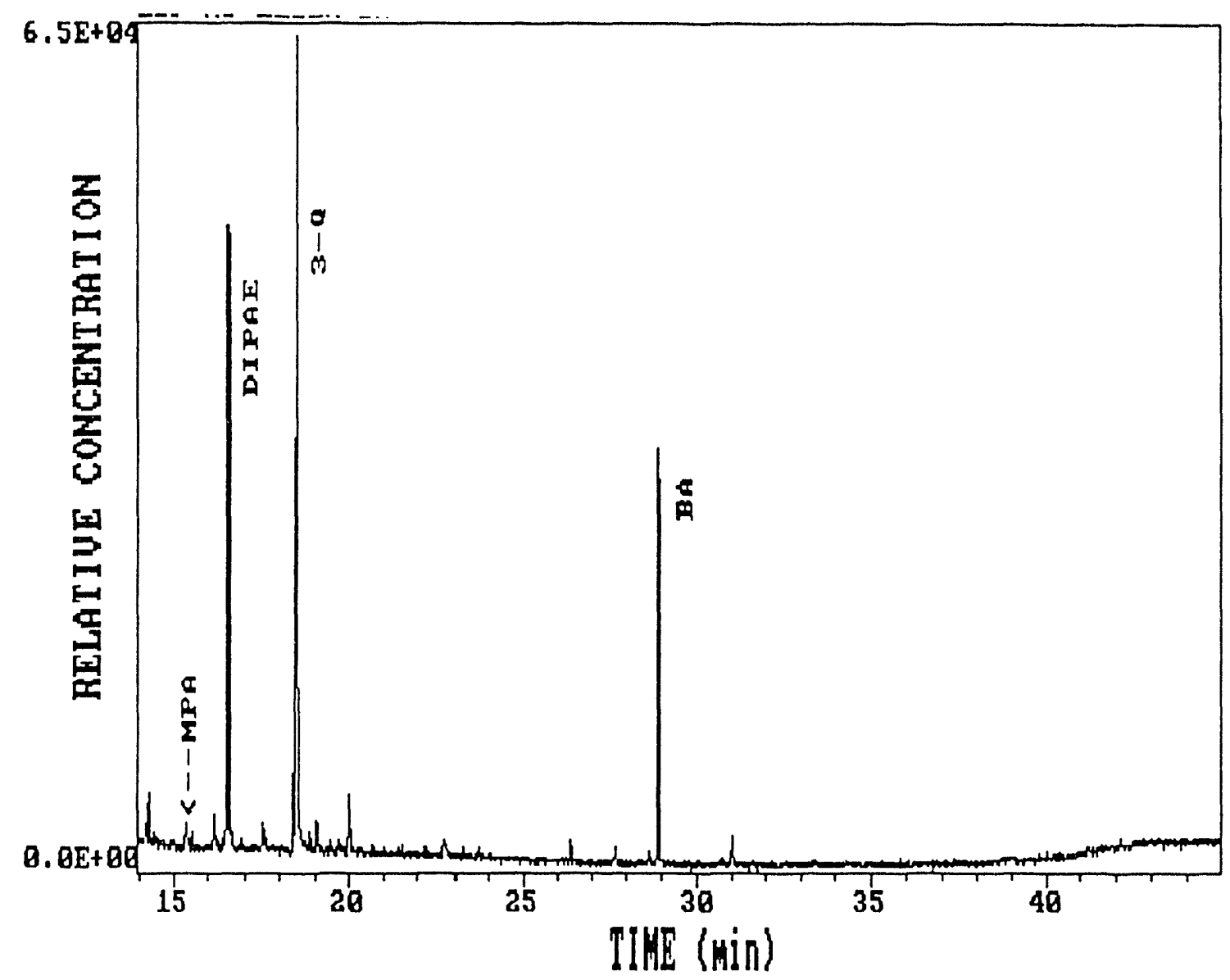




\section{APPENDIX 1}

List Of Laboratory Contacts Receiving Round Robin 4 Samples

1. Dr. Marjatta Rautio

Department of Chemistry

University of Helsinki

Vuorikatu 20, SF-00100

Helsinki, Finland

2. Dr. Robert Matthews

Dept. of Defence Materials Research Laboratory

Defence Science and Technology Organization, (DSTO, MRL)

P.O. Box 50

Ascot Vale, Victoria, Australia

3. Dr. Camille Boulet

Defence Research Establishment Suffield (DRES)

Box 4000, Medicine Hat

Alberta, T1A 8K6, Canada

4. Dr. Gu Huifen

Institute of Chemical Defence CPLA

P.O. Box 1048 (No. 8)

Beijing, China, 102205

5. Dr. J. Cermak

Research Institute of Organic Syntheses

53218 Pardubice-Rybitvi

Czech and Slovak Federal Republic

6. Dr. Frederic Guir

Centre d'Etudes du Bouchet (CEB)

B.P. 3, 91710 Vert le Petit

France

7. Dr. Stefan Kremer

Wehrwissenschaftliche Dienstelle der Bundeswehr fur ABC-Schutz

Humboltstrasse, Postfach 1142

W-3402 Munster, Germany

8. Dr. Eric Wils

Prins Maurits Laboratory, TNO

P.O. Box 45,

2280 AA Rijswijk ZH, The Netherlands 
9. Dr. John Aa Tornes

Norwegian Defence Research Establishment

P.O. Box 25

N-2007 Kjeller, Norway

10. Dr. Sten Ake Fredriksson

National Defence Research Establishment

Department of NBC-Defence

S-901 82 Umea, Sweden

11. Dr. Walter Aue

Defence Technology and Procurement Agency

NC Laboratory

$\mathrm{CH}-3700$ Spiez, Switzerland

12. Laboratory of the Ministry of Chemical and Petrochemical Industry of the Russian Federation, Volsk

Ministry of Foreign Affairs / Pjatkov

Moscow, The Russian Federation

13. Center for Ecotoximetry of the Academy of Science of

The Russian Federation, Moscow

Ministry of Foreign Affairs / Pjatkov

Moscow, The Russian Federation

14. Dr. Paul Norman

Chemical and Biological Defence Establishment

Porton Down, Salisbury

Wiltshire, SP4 0JQ, The United Kingdom

15. Commander

US Army Edgewood Research, Development and Engineering Center

Attn. SCBRD-ENO-T / Dr. Dennis Reutter

Bldg. E 3320

Aberdeen Proving Ground, MD. 21010-5423 


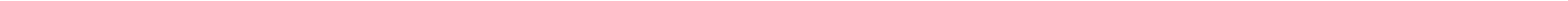


